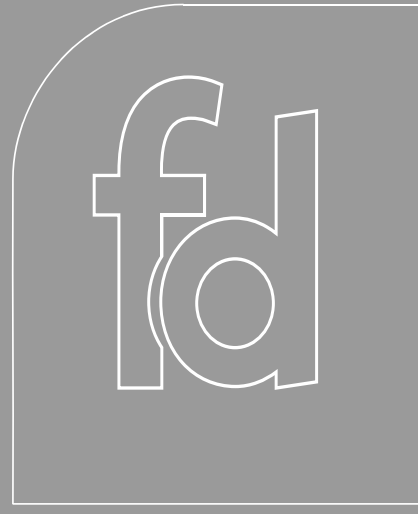

Local therapy of breast cancer: surgery

Local therapy of breast cancer: radiation therapy

Regional therapy of breast cancer

Expert commentary

Key issues

References

Affiliation

\author{
University of Michigan \\ Comprehensive Cancer Center, \\ 3304 Cancer Center, Division of \\ Surgical Oncology, 1500 East \\ Medical Center Drive, Ann Arbor, \\ MI 48109, USA \\ Tel.: + 17349365827 \\ Fax: +17346479647 \\ msabel@umich.edu \\ KEYWORDS: \\ breast cancer, breast conservation, \\ in situ ablation, mastectomy, \\ neoadjuvant chemotherapy, \\ partial breast irradiation, sentinel \\ lymph node biopsy
}

\title{
Locoregional therapy of breast cancer: maximizing control, minimizing morbidity
}

\author{
Michael S Sabel
}

The goal of locoregional therapy in breast cancer has remain unchanged for a century: the eradication of all malignant cells from the breast and draining lymph nodes, hopefully prior to them having spread to distant organs. However, how we accomplish this goal has changed dramatically over this time period and our success in achieving this goal has been greatly enhanced by improvements in breast imaging and systemic therapies. The therapeutic importance of surgery and radiation has been underestimated in recent years and thought to have minimal impact on long-term outcome. More recent data have reputed this contention and the relationship between local control and survival in breast cancer is becoming increasingly apparent. This article will review the importance of attaining optimum local control with minimum morbidity and examine where the future of locoregional therapy of breast cancer may lie.

Expert Rev. Anticancer Ther. 6(9), 1261-1279 (2006)

For all the changes in breast cancer management, the paradigm of locoregional therapy for breast cancer is the same today as it was when Halsted described the radical mastectomy over 100 years ago [1]. Halsted's theory, although much maligned today, hinged upon the idea that there exists a population of breast cancer patients with disease in their breasts, which may have already spread to the lymph nodes, but has not yet metastasized elsewhere and for whom surgery will be curative. While Halsted was wrong in his assertion that the cancer progressed systematically from the breast to the nodes and then distally, what ultimately doomed his theory was his underestimation of the extent to which breast cancer had already metastasized and was beyond surgical cure at the time of diagnosis. Thus, the radical mastectomy, while dramatically affecting local recurrence rates, had no impact on overall survival [2].

When it was demonstrated that equivalent outcomes could be obtained with less drastic surgery, despite increased local recurrence rates [3], the paradigm changed. Breast cancer was thought of as a systemic disease from its inception, and the management of the disease in the breast and regional nodes would have minimal impact on the survival of the patient. While this helped usher in the increased use of systemic therapies and the dramatic impact they have had on breast cancer mortality, this paradigm was also slightly flawed. It failed to fully appreciate the temporal relationship between the primary cancer and the likelihood of distant disease, thereby diminishing the importance of screening, early detection and local therapy. It also downplayed the impact that local-regional control could have on overall survival. However, more recent evidence demonstrates how important local control is on long-term survival.

As surgeons, our goals today are essentially the same one that Halsted espoused; the eradication of all malignant cells from the breast and draining lymph nodes, hopefully at a time point prior to them having spread elsewhere. This possibility is more likely than during Halsted's era, given the smaller size at which breast cancers can be detected. In addition, there are effective systemic therapies to cure an additional subset of patients beyond the reach of surgery alone. However, the therapeutic importance of surgery and radiation should 
not be underestimated and, while the goal of therapy may be the same today as it was a century ago, the morbidity needed to achieve that goal has changed dramatically.

\section{Local therapy of breast cancer: surgery Breast conservation versus mastectomy}

The evolution of breast cancer surgery through the radical, extended radical and modified radical mastectomies, has been well described, as have the randomized trials (now $>20$ years old) that established the equivalent survival of breast conservation therapy (BCT) [4-10]. In addition to the randomized data, a quarter century of experience has clearly demonstrated the appropriateness of lumpectomy and wholebreast irradiation. Today, the discussion must focus on the optimum use of BCT, as well as methods for improving both the applicability and cosmetic outcome of BCT, without compromising the results.

Despite the overwhelming evidence in favor of BCT for appropriate patients, there still exists wide variability in its application [11-17]. Some patients are not appropriate candidates for lumpectomy and some women, while technically candidates for BCT, will be better served by a mastectomy. Simply because a lumpectomy can be performed does not mean that the cosmetic result obtained will be satisfactory, or superior to that obtained with a mastectomy and reconstruction. This is particularly true with the advent of skin-sparing mastectomy and improvements in autologous flaps [18-21]. Nonetheless, many women for whom BCT would provide both excellent control and cosmetics are still undergoing mastectomies.

The reasons for this are multifactorial [22]. Part of this rests with physicians [23]. Many doctors recommend mastectomy if they estimate the 5-10-year risk of in-breast recurrence to be greater than $10-15 \%$, thus women with higher risk lesions are more likely to undergo mastectomy. However, many physicians overestimate the risk of local recurrence based on these features and do not appreciate that the risk of local recurrence among these patients is elevated for both BCT and mastectomy.

Conversely, part of the underutilization of BCT is related to patient preference. In some cases, the physician may not clearly communicate to the patient the equivalence of the procedures or the differences between a local recurrence and a distant recurrence. However, armed with the appropriate information, it is not unreasonable for a patient to choose mastectomy. For any individual patient, the desire to avoid a second operation in the future or the time commitment and side effects of radiation therapy may outweigh their perceptions of the cosmetic or psychosocial implications of mastectomy.

Several studies have examined the intricacies involved in how patients choose between BCT and mastectomy, and much of this involves the perceived decision-making process between surgeon and patient [22,24-27]. It is therefore incumbent upon physicians to correctly exclude those patients for whom breast conservation is contraindicated, accurately communicate the relative advantages and disadvantages of the two approaches and then guide the patient through the decision- making process (including the involvement of plastic surgeons, radiation oncologists, social workers and/or therapists if necessary).

\section{Contraindications to breast conservation}

Not all patients are suitable candidates for breast conservation [28]. Before any patient is considered for breast conservation, they must satisfy three criteria. The first is the ability to achieve adequate negative margins around the cancer. The second is the ability to undergo breast irradiation; and the third is the likelihood of achieving a cosmetically acceptable result after surgery and radiation therapy. This third criterion is somewhat more subjective, as some patients with significant defects or volume loss may still find the end result more cosmetically appealing than a mastectomy with reconstruction.

Patients who have undergone prior chest wall irradiation should not undergo a second dose of radiation and, therefore should undergo mastectomy rather than lumpectomy. The most common example is the patient who was previously treated by breast conservation and now has a second primary tumor in the ipsilateral breast (or a local recurrence). Another example is the woman treated with irradiation for Hodgkin's disease. A second group of patients who can not undergo radiation therapy are patients with collagen-vascular disease, particularly scleroderma. These patients may experience excessive radiation toxicity and should avoid BCT [29-31]. Patients in their first or second trimester of pregnancy also cannot receive radiation, as there is no way to adequately protect the fetus. Women in their third trimester may undergo lumpectomy and defer the radiation until after delivery. In some cases, where adjuvant chemotherapy is indicated, patients in their second trimester may consider lumpectomy followed by adjuvant chemotherapy, with the radiation delivered after delivery.

If the surgeon is unable to obtain negative margins around the cancer, then mastectomy is indicated. How many attempts at reexcision is up to the surgeon and the patient, and depends upon her motivation for breast preservation, the likelihood of obtaining negative margins and how much volume loss the breast can accommodate. Multifocal disease is not a contraindication to breast conservation, assuming negative margins can be obtained. However, multicentric disease, defined as tumors in separate quadrants of the breast, is an indication for mastectomy. Even if two lumpectomies could be performed, there is likely microscopic disease elsewhere in the breast and recurrence rates are excessively high [32-34]. If multiple tumors are in close proximity and can be encompassed in one margin-negative lumpectomy specimen, this is also acceptable for BCT [35].

\section{Not contraindications to breast-conserving therapy}

Many physicians incorrectly include other factors that have been associated with a heightened anxiety about the risk of recurrence, but in fact are not contraindications to BCT. Several features of the primary tumor, such as multifocality, an extensive intraductal component (EIC) and histologies, such as lobular carcinoma, are associated with tumors that extend farther than 
anticipated on preoperative imaging studies and may require wider margins of excision to achieve negative margins. Often, a re-excision lumpectomy is necessary for a close or positive margin. In some cases, this will tilt things in favor of mastectomy if the resultant larger cavity would not be cosmetically acceptable. However, these features in themselves are not contraindications as long as negative margins are obtained.

A common misconception is that axillary nodal metastases, since they are associated with an increased risk of local recurrence, are an indication for mastectomy. This is not true, as the presence of nodal metastases also increases the risk of chest wall recurrence after mastectomy. In addition, the increased likelihood of distant metastases in node-positive women decreases the relative impact that local control will have on survival. Thus, there is very little reason why women with nodal involvement can not undergo breast conservation.

Older women more commonly undergo mastectomy, partially due to patient preference, but partially due to physician recommendations [22,36]. Age is not a contraindication to breast conservation. This is true for both older women, whose suitability for surgery or radiation should be based on their physiological age and comorbidities, and younger women. While increased rates of local recurrence have been described in younger women [37,38], the increased local recurrence rates are often secondary to surgeon reluctance to take appropriate margins for fear of disturbing the cosmetic result [39]. If negative margins can be obtained with an acceptable cosmetic result, young age itself should not prompt a recommendation of mastectomy.

Finally, there is the issue of a strong family history of breast cancer or a known BRCA1 or BRCA2 mutation. Women with a family history of breast or ovarian cancer should be informed of their risk of a second primary cancer and considered for genetic counseling and genetic testing, as this may ultimately help them decide whether bilateral mastectomy is warranted. However, if they opt not to proceed with bilateral mastectomy for treatment and prophylaxis, they do not require unilateral mastectomy instead of BCT to control their existing disease [40,41].

\section{Increasing candidacy for BCT with neoadjuvant chemotherapy}

One of the more common reasons a woman is not considered a candidate for BCT is the size of her tumor relative to the size of her breast. Breast conservation is hardly justified if the cosmetic result is undesirable owing to an unacceptably large defect or volume discrepancy. However, the size of the tumor is not an absolute contraindication to BCT. The delivery of systemic therapy prior to surgical intervention (neoadjvuant therapy) may decrease the size of the primary tumor. This allows for the potential resection of an inoperable cancer, or the use of BCT in a case where a mastectomy would have been indicated [42].

Using systemic therapy upfront is considered the standard treatment for patients who present with inoperable breast cancer. This includes patients with locally advanced tumors (T4 tumors), inflammatory breast cancer and patients with involvement of the supra or infraclavicular lymph nodes (N3). The success of primary systemic therapy in locally advanced breast cancer led to the suspicion that it may be preferable in operable breast cancer; that delivery of chemotherapy before surgery may increase survival by treating the occult micrometastases at an earlier time point. However, the large randomized trials of preoperative chemotherapy demonstrated equivalent disease-free and overall survival. The trials did demonstrate, however, that there was a higher rate of breast-conserving surgery in the patients who received neoadjuvant chemotherapy (TABLE 1).

Are local recurrence rates comparable after downstaging a tumor with chemotherapy? Of the major randomized studies of neoadjuvant chemotherapy, local recurrence rates have been either equivalent or higher in the preoperative chemotherapy arms, but within acceptable limits. Local recurrence rates varied between 3 and 27\%, depending upon the duration of followup, type of surgery and margins obtained. The largest study, National Surgical Adjuvant Breast and Bowel Project (NSABP) B-18, which involved over 1500 women with stages I through IIIA breast cancer, demonstrated a statistically significant increase in breast conservation (68 vs $60 \%$ ), but with a median follow-up of 72 months, there was no statistically significant difference in local recurrence following BCT (7.9 vs $5.8 \%$ ) [43]. However, this includes those patients who were candidates for lumpectomy before they received their chemotherapy. Looking at just those patients who would have required mastectomy, but were downstaged to become eligible for BCT, the rate of local recurrence was $16 \%$ compared with the $10 \%$ of patients who were considered candidates for BCT before chemotherapy. One must keep in mind, however, that most of these were T3 tumors and would have had an increased rate of chest wall recurrence had mastectomy been performed.

There are many additional advantages to neoadjuvant chemotherapy, such as the early initiation of systemic therapy, the evaluation of an individual's response to chemotherapy (possibly allowing for a change in therapy if the patient is not responding), and delaying surgery so that patients may deal

Table 1. Impact of neoadjuvant chemotherapy on breast conservation, data from selected randomized trials.

\begin{tabular}{|c|c|c|c|c|c|}
\hline \multirow[t]{2}{*}{ Study } & \multirow[t]{2}{*}{$\mathrm{N}$} & \multirow{2}{*}{$\begin{array}{l}\text { Tumor } \\
\text { size/stage }\end{array}$} & \multicolumn{2}{|c|}{ BCT rate } & \multirow[t]{2}{*}{ Ref. } \\
\hline & & & Neoadjuvant & Adjuvant & \\
\hline $\begin{array}{l}\text { Institute } \\
\text { Bergonie }\end{array}$ & 272 & $\mathrm{~T}>3 \mathrm{~cm}$ & $63.1 \%$ & $0 \%$ & {$[193,194]$} \\
\hline $\begin{array}{l}\text { Royal } \\
\text { Mardsen }\end{array}$ & 309 & $|-||| B$ & $89 \%$ & $78 \%$ & [195] \\
\hline $\begin{array}{l}\text { Institute } \\
\text { Curie }\end{array}$ & 414 & $\|A-I\| A$ & $82 \%$ & $77 \%$ & [196] \\
\hline EORTC & 698 & $\mid-\| A$ & $37 \%$ & $21 \%$ & [197] \\
\hline $\begin{array}{l}\text { NSABP } \\
\text { B-18 }\end{array}$ & 1523 & $|-||| A$ & $68 \%$ & $60 \%$ & [43] \\
\hline
\end{tabular}

BCT: Breast conserving therapy; EORTC: European Organization for Research and Treatment of Cancer; N: Number of patients; NSABP: National Surgical Adjuvant Breast and Bowel Project. 
with issues related to the extent of surgery and reconstructive options. In addition, clinical trials in the neoadjuvant setting have facilitated the discovery of new chemotherapeutic agents. However, it should be remembered that for the patient with operable breast cancer, the primary indication for neoadjuvant chemotherapy is downstaging the primary tumor in patients who desire breast conservation. Delivering the chemotherapy preoperatively is an alternative to adjuvant chemotherapy. The determinant for the use of chemotherapy is the risk of distant recurrence, so neoadjuvant chemotherapy should only be offered to patients who, based on clinical staging (e.g., tumor size, grade, estrogen receptor $[\mathrm{ER}] /$ progesterone receptor $[\mathrm{PR}]$ status and palpable lymph nodes), would be candidates for chemotherapy.

\section{The future: in situ ablation}

While chemotherapy can expand the range of BCT to women with large primary tumors, that patient is becoming increasingly rare. Today, with increased screening and more sensitive imaging, a greater percentage of patients are being diagnosed with

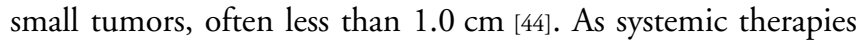
become more effective and their use in the neoadjuvant setting expands, another subset of women will have their primary tumors significantly downstaged. While a lumpectomy followed by radiation therapy is a significant esthetic improvement over a mastectomy, it is still an invasive procedure resulting in a scar and often a cosmetic defect in the breast.

As we expand our abilities in image-guided biopsies, a similar enthusiasm exists for image-guided treatment. There is intense interest in the possibility of ablating small cancers within the breast, without the need for surgery. In addition to greatly improving cosmetic outcomes, this could reduce the demands for operating-room time, decrease recovery time and complications, and lessen healthcare costs. Several methods of tissue ablation have been used for other cancers and are being investigated as a treatment for breast cancer.

Cryoablation, which destroys tumors by freezing tissue below $-160^{\circ} \mathrm{C}$, has attracted considerable attention. With ultrasound guidance, a cryoprobe can be inserted through a tiny incision in the breast and placed directly into the center of the tumor. Liquid nitrogen or argon gas flows through the cryoprobe, freezing the tip and generating an iceball around the tumor and surrounding tissue. This can be monitored with ultrasound to ensure the cancer is completely encompassed and prevent damage to the overlying skin. Cryoablation has been approved for the treatment of benign fibroadenomas [45] and cryo-assisted lumpectomy is being examined as a method of excising nonpalpable lesions [46]. Cryoablation alone may also someday replace lumpectomy for patients with small primary tumors. Along with preclinical studies, Staren and colleagues initially described a case of a patient with two foci of infiltrating lobular carcinoma $(0.5$ and $0.8 \mathrm{~cm})$ who was successfully treated by cryoablation [47]. This led to several small trials of cryoablation followed by surgical excision, to better gauge the ability of cryoablation to completely destroy breast tumors [48-50]. While cryoablation was effective at ablating invasive ductal carcinomas of $1.5 \mathrm{~cm}$ or less, it was less effective when used to ablate larger tumors, lobular carcinomas or tumors with an extensive intraductal component. The latter two represent an inability of present imaging modalities (e.g., mammogram and ultrasound) to fully show the extent of the cancer, particularly the in situ component. With improved imaging, such as magnetic resonance imaging (MRI), patients may be better selected for cryoablation. Cryoablation is particularly attractive as a method for treating small breast cancers as it is easy to perform under ultrasound guidance, is associated with minimal to no discomfort, can be performed with local anesthesia only, has an excellent cosmetic result and may stimulate an anti-tumor immune response with implications beyond local control [48,51]. A Phase II trial of cryoablation is currently accruing patients.

In contrast to cryoablation, several modalities use high temperatures to destroy cancer. Radiofrequency ablation (RFA) uses high-frequency alternating current flows from the tips of an array of prongs that are deployed from the tip of a probe placed into the tumor. RFA leads to coagulative necrosis of the ablated tissue. RFA has typically been performed with sedation or general anesthesia. Several small series have examined the potential of RFA in breast cancer, starting with a pilot trial by Jeffrey and colleagues, who successfully treated four out of five women with large primary tumors $(4-7 \mathrm{~cm})$. Three larger series of RFA for smaller tumors showed high rates of complete tumor ablation, with minimal complications, although skin burns can occur and women with lesions too close to the skin are not optimal candidates [52-55]. MRI may be a valuable tool in selecting appropriate patients for RFA and monitoring the response to therapy [56]. Interstitial laser ablation (ILA) represents another hyperthermia-based ablative technology. This requires the insertion of a laser-emitting optic fiber into the center of a tumor to destroy the cancer. Using a field block, this has been successfully performed without intravenous sedation [57]. Placement of the fiber can be accomplished by either stereotactic or MRI guidance [57-61].

The above techniques are minimally invasive; they require a small incision in the skin followed by guidance of a probe or catheter to the center of the tumor. Other technologies are being developed that are truly noninvasive. Microwave ablation uses two microwave-phase array wave guide applicators to generate thermal energy [62]. This technology takes advantage of the fact that breast cancer cells have higher water content than normal breast cells, so they heat more rapidly during microwave ablation. Early trials have demonstrated the feasibility of this technique, but further refinements are necessary to improve the clinical applicability [63,64]. Focused ultrasound (FUS) ablation is another noninvasive technique that uses ultrasound beams to ablate a very well defined target in the breast. Since MRI yields such excellent anatomic resolution, it is ideal for guiding FUS. FUS has been performed without anesthesia or discomfort, although some minor skin burns have occurred. Again, early results are intriguing but further refinements of the technology are necessary $[65,66]$. 
Table 2. Clinical studies of in situ ablation of breast cancer.

\begin{tabular}{|c|c|c|c|c|}
\hline Technology & $\mathbf{N}$ & Tumor size & Results & Ref. \\
\hline RFA & 10 & $0.5-2.0 \mathrm{~cm}$ & $\begin{array}{l}\text { No viable tumor cells on NADH-diaphorase staining in the RF-ablated region in all } \\
\text { patients }\end{array}$ & [198] \\
\hline RFA & 5 & $4-7 \mathrm{~cm}$ & Complete ablation in $4 / 5$ patients & [199] \\
\hline RFA & 26 & $\mathrm{~T} 1-\mathrm{T} 2$ & Complete ablation in $25 / 26$ patients. One skin burn & [53] \\
\hline RFA & 29 & $<2.0 \mathrm{~cm}$ & Complete ablation in $25 / 29$ patients. One skin burn & {$[55]$} \\
\hline RFA & 10 & $\mathrm{~T} 1$ & Complete ablation in 9/10 patients. No complications & [56] \\
\hline RFA & 22 & $<3.0 \mathrm{~cm}$ & $\begin{array}{l}\text { Complete ablation in } 19 / 22 \\
\text { No complications. }\end{array}$ & [200] \\
\hline Cryosurgery & 16 & Average $21 \mathrm{~mm}$ & Complete ablation $<16 \mathrm{~mm}$, but not $\geq 23 \mathrm{~mm}$. No complications & [49] \\
\hline Cryosurgery & 29 & $<2 \mathrm{~cm}$ & Complete ablation for invasive ductal, no EIC $<1.5 \mathrm{~cm}$. No complications & [48] \\
\hline Cryosurgery & 25 & $2.0-6.0 \mathrm{~cm}$ & $\begin{array}{l}\text { Complete ablation in } 13 / 25 \text { patients } \\
\text { MRI and scintimammography correlated with success of cryo }\end{array}$ & [50] \\
\hline ILA & 54 & $<23 \mathrm{~mm}$ & $\begin{array}{l}\text { Residual disease in } 16 / 54 \text { patients } \\
\text { Two minor skin burns }\end{array}$ & [58] \\
\hline Microwave & 10 & $1-8 \mathrm{~cm}$ & 6/10 tumors shows some size reduction. & [63] \\
\hline Microwave & 25 & Average $1.8 \mathrm{~cm}$ & $100 \%$ tumor response with $49.7^{\circ} \mathrm{C}$ & [64] \\
\hline Focused ultrasound & 12 & $<3.5 \mathrm{~cm}$ & Two minor skin burns & [66] \\
\hline Focused ultrasound & 23 & $2.0-4.7 \mathrm{~cm}$ & $\begin{array}{l}\text { No viable tumor cells on NADH-diaphorase staining in the RF-ablated region in all } \\
\text { patients }\end{array}$ & [201] \\
\hline
\end{tabular}

EIC: Extensive intraductal component; ILA: Interstitial laser ablation; MRI: Magnetic resonance imaging; NADH: Nicotinamide adenine dinucleotide;

RFA: Radiofrequency ablation

Although image-guided ablation of breast cancer would be a tremendous boon to women with small breast cancers, the technologies are still quite early in their development, with limited clinical experience (TABLE 2). Considerable research is still necessary to improve their capabilities and define their role. As imaging technologies improve, so will the ability of in situ ablation to more reliably destroy cancers, but this technology is still many years away from replacing lumpectomy.

\section{Local therapy of breast cancer: radiation therapy}

Several of the randomized trials that established the efficacy of breast conservation included arms where women underwent lumpectomy alone, without radiation. These studies demonstrated no significant survival difference between those two groups, despite a significant increase in local recurrence. This led to a shift in the way we think about breast cancer and, unfortunately, is often interpreted as 'local recurrence has no impact on survival'. For this reason, physicians are often willing to offer local therapies with an exceptionally high local recurrence rate under the impression that if patients do recur and undergo salvage mastectomy, this had no negative impact on their survival. While it has long been known that women who do recur have a higher incidence of developing distant disease, this has often been attributed to a more aggressive cancer being responsible for both local and distant recurrences. There was little evidence that preventing the local recurrence would have prevented the distant disease.
The original randomized trials that demonstrated no difference in survival between lumpectomy alone and lumpectomy with radiation did not have the power to detect a small survival advantage from the addition of RT. In addition, the morbidity and mortality associated with RT negated some survival advantage, particularly with older methods for delivering radiation. More recent data have refuted the notion that local control has no impact on overall survival. The most recent update of the Early Breast Cancer Trialists Collaborative Group (EBCTCG) meta-analysis demonstrates that the 15-year breast cancer mortality risks were significantly lower in the patients who received RT (30.5 vs 35.9; p = 0.002) [67]. A pooled analysis of mortality data from 13 randomized trials also showed a worse survival in women who did not receive RT, with an $8.6 \%$ excess mortality [68]. These data clearly demonstrates that improved local control does impact survival, and women with an exceedingly high risk of in-breast recurrence with BCT compared with mastectomy may be better served by the latter. It also establishes that radiation is a critical component of BCT.

\section{Radiation as a component of breast conservation}

The improved local control rate achieved with RT is impressive. The EBCTCG meta-analysis demonstrated a 5-year local recurrence rate of $7 \%$ for breast conservation with RT and $26 \%$ when RT was excluded [67]. While these data clearly cement the routine addition of radiation to lumpectomy for optimal local 
control, the question remains as to whether or not there exist subsets of patients for whom the in-breast recurrence risk is low enough that RT may be excessive. Attempts to identify such a subset of patients, who have a low enough risk of local recurrence to justify surgery alone, have not been successful. In a prospective trial of women with the most favorable features (tumor size $\leq 2 \mathrm{~cm}$, histologically negative axillary nodes, absence of angiolymphatic invasion or EIC and margins $>1 \mathrm{~cm}$ ) who underwent surgery alone, the trial had to be stopped early owing to the high local recurrence rate (20\%) [69]. NSABP B-21 included 1009 women undergoing lumpectomy for invasive breast cancer less than or equal to $1 \mathrm{~cm}$ in size and found that women treated by lumpectomy with tamoxifen had a $16.5 \%$ local recurrence rate compared with $2.8 \%$ for lumpectomy, radiation and tamoxifen (and 9.3\% for lumpectomy and RT without tamoxifen) [70]. This demonstrates that even with the use of systemic therapy, RT significantly decreases local recurrence in patients with small tumors.

One subset of patients for whom the avoidance of radiation seems possible is older women with hormone receptor-positive tumors. Several retrospective series of conservative surgery alone in older women have shown varying rates of local recurrence, but similar distant recurrence and survival rates [71-73]. Two randomized trials have shown comparable results. In a Canadian trial randomizing women over the age of 50 years undergoing lumpectomy with adjuvant tamoxifen to radiation or none, RT significantly decreased the risk of local recurrence ( 17.6 vs $3.5 \%$ at 8 years), but did not appear to impact rates of distant metastases, overall survival and the number of deaths due to breast cancer [74]. However, given what we now appreciate regarding local control and overall survival, this local recurrence rate seems uncomfortably high. A Cancer and Leukemia Group B (CALGB) trial of women over the age of 70 years also showed a difference in the risk of local recurrence in women treated with tamoxifen with or without RT (4 versus $1 \%$ ), but no impact on overall survival ( 86 vs $87 \%$ at 5 years) [75]. Rates of mastectomy for local failure were also similar. While the Canadian trial included tumors up to $5 \mathrm{~cm}$, the CALGB trial was limited to tumors less than $2 \mathrm{~cm}$. Thus, in selected women over the age of 70 with small ER-positive breast cancer, treatment with tamoxifen alone may be a reasonable option.

\section{Postmastectomy radiation}

It is often presented to patients that one of the advantages of mastectomy over breast conservation is that RT will not be necessary. However, chest wall recurrence after mastectomy alone is not an infrequent event. The risk of locoregional failure after mastectomy increases with increasing tumor size [76,77], as well as increasing numbers of involved axillary nodes [76-79]. Early trials of postmastectomy radiation, accruing patients in the 1960s and 1970s, demonstrated that while radiation decreased chest wall recurrences, there was no significant increase in overall survival compared with control patients, and possibly a decreased survival [80]. However, meta-analysis of these trials, with long-term follow-up and cause-specific mortality recorded, suggested that mortality from late cardiac effects were responsible for canceling out any survival advantage to RT, something not present to the same degree today using modern RT techniques. The most recent meta-analysis by the Early Breast Cancer Trialists' Collaborative, including 46 randomized trials involving over 23,000 patients, found that postmastectomy RT was associated with a significant reduction in both local recurrence ( 5.8 vs $22.8 \%$ at 5 years) and in breast cancer mortality for node-positive women (54.7 vs $60 \% ; \mathrm{p}=0.0002$ ) [67].

Several trials using more modern radiotherapy and adjuvant systemic therapy have further demonstrated the impact of postmastectomy radiation. The first Danish Breast Cancer Cooperative Group trial included 1708 premenopausal women with either positive nodes or T3 or T4 tumors to undergo A Cancer and Leukemia Group B (CALGB) and then be randomized to receive chest wall and regional nodal irradiation or not [81]. With a median follow-up of approximately 10 years, postmastectomy radiotherapy was associated with a significant improvement in locoregional failure (32 vs 9\%), disease-free survival (48 vs $34 \%$ ) and overall survival (54 vs $45 \%$ ). However, this trial required only axillary sampling, not a complete dissection and most recurrences were in the axilla, a relatively rare occurrence in patients who had a level I and II dissection [82]. It is unclear what the results of this trial would have been had the patients had a complete Axillary lymph node dissection (ALND), as is performed routinely in the USA.

In the British Columbia trial, 318 premenopausal women with node-positive breast cancer undergoing modified radical mastectomy were randomly assigned to cyclophosphamide, methotrexate and fluorouracil (CMF) plus chest wall radiotherapy versus CMF alone [83]. Improvements in local-regional recurrence and DFS were again seen, with a trend towards improved survival. With 20-year follow-up, the overall survival benefit was statistically significant (overall survival: 47 vs $37 \%$; hazard ration [HR]: 0.73 95\%; confidence interval [CI] 0.55-0.98) [84]. A third trial, also from the Danish Breast Cancer Cooperative Group, randomized 1375 postmenopausal women with stage II or III breast cancer to adjuvant tamoxifen $(30 \mathrm{mg} /$ day for 1 year) alone or with postoperative chest wall irradiation [85]. Once again, significant improvements were seen with postmastectomy RT with regards to local-regional recurrence (8 vs $35 \%$ ), 10-year DFS (36 vs $24 \%$ ) and overall survival ( 45 vs $36 \%$; $\mathrm{p}=0.03$ ).

Based on these studies, postmastectomy radiation is recommended for several subsets of patients [86]. Patients with four or more positive lymph nodes clearly benefit from postmastectomy RT. The data are less clear for patients with one to three positive nodes. While the impact of treatment on survival might be similar, the risk of recurrence and death is less, and given the questions regarding the surgery used in the Danish trials, it is difficult to translate these findings to the American practice of axillary clearance. For now, there is insufficient evidence to recommend routine chest wall RT for women with one to three axillary nodes, but these women should have the relative pros and cons of postmastectomy radiation presented to 
them. Other patients who should undergo postmastectomy RT include women with T3 and T4 tumors, those with positive margins after mastectomy, patients with advanced nodal disease (N2 or N3) or with gross extranodal extension.

It is important to keep in mind that if postmastectomy radiation is to be utilized, this may impact the timing and method of reconstruction. The cosmetic outcome of immediate breast reconstruction will be affected by radiation. This is particularly true if tissue expanders and implants are used, but radiation can also negatively affect autologous reconstructions. Another lessrecognized problem is that the reconstruction can negatively impact the delivery of radiation [87]. One option is to simply delay reconstruction until all treatment is completed. However, if immediate reconstruction is desired, there are options. If the nodal status is the question, one option is to perform the SLN biopsy as a separate procedure prior to mastectomy. This can be combined with ligation of the inferior epigastric vessels when indicated for reconstruction purposes. If the SLN is negative, the next step is mastectomy and reconstruction. If the patient is node positive, reconstruction can be delayed, especially if tissue expanders were planned. An alternate approach used at the MD Anderson Cancer Center is to conduct a delayed-immediate reconstruction [88]. The first stage consists of a skin-sparing mastectomy followed by a tissue expander. Once the pathology is reviewed, if patients will not require radiation, they return to the operating room for immediate reconstruction. If radiation is to be used, the tissue expander is fully deflated and then reinflated after radiation, followed by delayed breast reconstruction.

\section{The future: partial breast irradiation}

Standard radiation therapy after breast conservation uses a total dose of 45-50 Gy in single fractions of 1.8-2.0 Gy each, delivered to the entire breast. Because most local recurrences occur close to site of the lumpectomy, a boost of 12-20 Gy to the tumor bed is often recommended, extending the time necessary for treatment. The argument for treating the entire breast is based on pathological studies of mastectomy specimens. In the classic study by Holland and colleagues, $27 \%$ of patients had tumor cells outside of a $2 \mathrm{~cm}$ margin of the primary tumor [89]. However, standard whole-breast irradiation can often add additional inconvenience and cost to both the patient and the healthcare system [90]. The time and travel involved are often a burden on women, so many women who are candidates for BCT may still choose mastectomy to avoid the inconvenience and toxicity of whole-breast irradiation.

Methods to decrease the time needed for whole-breast irradiation have been examined. One such approach is the use of more rapid fractionation schedules. As opposed to the standard 45-50 Gy over 35 days, shorter schedules may be used, such as 42.5 Gy over 22 days, as was found to be equivalent in a randomized trial from Canada [91]. However, the radiation component of breast conservation may change even more dramatically over the next few years. Recent observations that the overwhelming majority of local recurrences occur in close proximity to the tumor bed [92-97], has raised the question of whether or not whole-breast irradiation is truly necessary. Patients may receive the same benefit from irradiating only the tumor bed, sparing the remainder of the breast. This may not only improve the cosmetic outcome, but would shorten the costs associated with treatment and the time necessary to complete therapy. Several techniques for delivering partial-breast irradiation (PBI) have been evaluated [98].

Of all the techniques, multicatheter, interstitial brachytherapy has been in use the longest. Multiple hollow catheters are placed in the breast tissue around the lumpectomy cavity, depending on its size and shape. The radioactive source is then placed within the catheters. Either a continuous low dose rate (LDR) is delivered by leaving the radioactive sources in for $96 \mathrm{~h}$ (which requires admission to designated hospital rooms with radiation shielding), or a high dose rate (HDR) is used, typically twice daily for $30 \mathrm{~min}$, on an outpatient basis. Although catheter placement and dosimetry planning is complex, the procedure is surprisingly well tolerated by patients and can be used in a variety of situations, regardless of the size, shape or location of the lumpectomy cavity.

The MammoSite RTS is a balloon catheter device that greatly simplifies brachytherapy. A catheter sits centrally in a distally located balloon, resembling a Foley catheter. This is placed in the lumpectomy cavity, either at the time of surgery or as a second procedure, and inflated. Treatment is then delivered with a single, centralized HDR source. While much simpler than multicatheter brachytherapy, its use is limited to patients with adequate distance between the cavity and the skin, and a lumpectomy cavity that conforms well to the balloon surface. Use of MammoSite appears to be extremely safe and well tolerated [99], and early results seem promising [100].

As opposed to brachytherapy, external beam radiation can be used to deliver PBI. Recent technological advances in CT-based planning have allowed the introduction of $3 \mathrm{D}$ conformal external beam APBI. This allows for improved dose homogeneity within the target volume and does not require additional technology beyond what most radiation facilities already have. One disadvantage is that a larger area of normal breast tissue may need to be irradiated than with other PBI techniques, as the breast is a moving target. One way to improve upon this is the use of intensity-modulated radiation therapy (IMRT), which delivers radiation using a variable-intensity pattern that is determined with the aid of a computerized optimization algorithm [101-103]. While more costly and labor intensive than 3D conformal APBI, IMRT delivers a more uniform and standardized radiation dose without excessive treatment of the surrounding tissue. Finally, the need for post-operative radiation therapy can be avoided all together by the use of intraoperative radiation. Following lumpectomy, all of the adjuvant radiation is delivered in the operating room, using either low-energy $\mathrm{x}$ rays delivered by a portable, spherical device $[104,105]$, or by electrons generated by a mobile linear accelerator [106].

All of these technologies seem promising, but clinical experience is limited and long-term follow-up is not available for the newer approaches (TABLE 3). In addition, these trials are highly selective and, for the most part, from single institutions. Partic- 
Table 3. Selected studies of PBI in breast cancer.

\begin{tabular}{|c|c|c|c|c|}
\hline Method of PBI & $\mathrm{N}$ & Median F/U (months) & LRR (\%) & Ref. \\
\hline Multicatheter interstitial brachytherapy & 90 & 27 & 4.4 & [202] \\
\hline Multicatheter interstitial brachytherapy & 50 & 60 & 18 & [203] \\
\hline Multicatheter interstitial brachytherapy & 51 & 75 & 2 & [204] \\
\hline Multicatheter interstitial brachytherapy & 119 & 30 & 2.5 & [205] \\
\hline MammoSite & 43 & 29 & 0 & [99] \\
\hline External beam & 31 & 10 & 0 & [206] \\
\hline Intraoperative irradiation & 590 & 20 & 0.5 & [207] \\
\hline Multicatheter interstitial brachytherapy & 199 & 65 & 1.2 & [208] \\
\hline Multicatheter interstitial brachytherapy & 39 & 60 & 16.2 & [209] \\
\hline Multicatheter interstitial brachytherapy & 44 & 42 & 0 & {$[210]$} \\
\hline MammoSite & 28 & 19 & 0 & [211] \\
\hline MammoSite & 32 & 11 & 0 & [212] \\
\hline External beam & 47 & 18 & 0 & [213] \\
\hline Multicatheter interstitial brachytherapy & 99 & 44 & 3 & {$[214]$} \\
\hline Multicatheter interstitial brachytherapy & 99 & 38 & 2 & [215] \\
\hline
\end{tabular}

ipation is limited to a patient population with an expected excellent cosmetic outcome and low risk of recurrence with whole-breast irradiation (older patients, node negative, smaller tumors). PBI is presently being directly compared with wholebreast irradiation in a randomized trial, which will hopefully secure the role of PBI in BCT.

\section{Regional therapy of breast cancer}

The advent of SLN biopsy as a method for staging the axilla has dramatically changed the surgical staging of breast cancer. For all intents and purposes, ALND in clinically node-negative patients is no longer necessary unless the SLN biopsy is unsuccessful. The theory behind the SLN hypothesis is that tumor cells metastasize to the regional lymph nodes in a predictable and orderly fashion, so that the use of tracers injected in the breast and allowed to migrate to the regional nodes should accurately identify the node(s) most likely to harbor disease $[107,108]$. If, after serial sectioning, the SLN is negative, the likelihood of disease being present in other nodes should be very low, precluding the need for a more morbid ALND. Several studies have confirmed the accuracy of the procedure, including four systematic reviews [107,109-118]. The largest of these systematic reviews, performed by the ASCO expert guidelines panel, included 69 eligible trials of SLNB in early stage breast cancer, representing 8059 patients [118]. Overall, 95\% had a SLN successfully identified, with a false-negative rate of $8.4 \%$.

Many surgeons rapidly adopted sentinel node biopsy as the standard of care in breast cancer prior to any randomized controlled trial data. Several large nonrandomized series with reasonable follow-up, and one randomized trial, have demonstrated an extremely low regional recurrence rate among patients with a negative SLN and no completion ALND, suggesting that a negative impact on survival is highly unlikely [113-115]. However, it is worth mentioning that the patients included in these series were of surgeons with considerable experience with SLN biopsy and after an appropriate learning curve where the SLN biopsy was followed by an immediate ALND to accurately determine the false-negative rate. It is recommended that no surgeon begin performing SLN biopsy without completion ALND unless they have documented an adequate number of cases (20-30) where a suitably low false-negative rate is verified on completion ALND [119-122]. However, many surgeons have adopted this technique without documenting an adequate learning curve, which may adversely affect the false-negative rate as SLN biopsy becomes universal.

The only randomized trial published to date is a small study from Italy that randomized 516 patients to SLN biopsy plus ALND or SLN biopsy followed by ALND only if the SLN was positive [123]. There were no axillary recurrences in the group who did not proceed to have an ALND and short-term survival was the same for both groups. Several prospective, randomized trials are ongoing to address the impact of SLN biopsy on recurrence and survival (TABLE 4). The NSABP-B32, the ALMANAC and the SNAC trial have similar designs to the Italian trial, but are much larger, with the power to detect a small survival difference. Preliminary data show results similar to the systematic 
Table 4. Randomized studies of sentinel node biopsy in breast cancer.

\begin{tabular}{|c|c|c|c|c|c|}
\hline Study & Arms & Eligibility & Patients & Dates & Ref. \\
\hline \multicolumn{6}{|c|}{ Studies comparing ALND with SLN biopsy in clinically node-negative patients } \\
\hline NSABP-32 & ALND vs SLNB with ALND for SLN ${ }^{+}$ & Clinically node negative & 5612 & $\begin{array}{l}\text { Activated March, } 1999 \\
\text { Closed February, } 2004\end{array}$ & [216] \\
\hline Trial 185 & ALND vs SLNB with ALND for SLN ${ }^{+}$ & $\begin{array}{l}\text { Clinically node negative, } \\
\mathrm{T}<2 \mathrm{~cm}\end{array}$ & 516 & $\begin{array}{l}\text { Activated March, } 1998 \\
\text { Closed December, } 1999\end{array}$ & {$[123]$} \\
\hline ALMANAC & ALND vs SLNB with RT or ALND for SLN ${ }^{+}$ & $\begin{array}{l}\text { Clinically node negative, } \\
\text { T1 - T3 }\end{array}$ & 1031 & $\begin{array}{l}\text { Activated November, } 1999 \\
\text { Closed October, } 2003\end{array}$ & {$[217]$} \\
\hline RACS SNAC & ALND vs SLNB with ALND for SLN ${ }^{+}$ & $\begin{array}{l}\text { Clinically node negative, } \\
\text { T1 - T3 }\end{array}$ & 789 as of $11 / 03$ & Activated May, 2001 & {$[218]$} \\
\hline \multicolumn{6}{|c|}{ Studies evaluating treatment for sentinel node-positive patients } \\
\hline ACOSOG Z0011 & ALND vs observation for $\mathrm{SLN}^{+}$patients & $\begin{array}{l}\text { T1 or T2, } \\
\text { SLN positive }\end{array}$ & & $\begin{array}{l}\text { Activated November, } 2002 \\
\text { Closed owing to poor } \\
\text { accrual }\end{array}$ & {$[217]$} \\
\hline AMAROS-EORTC & ALND vs RT for SLN ${ }^{+}$patients & $\begin{array}{l}\mathrm{T}<3 \mathrm{~cm} \\
\text { SLN positive }\end{array}$ & & $\begin{array}{l}\text { Activated February, } 2001 \\
\text { Open to accrual }\end{array}$ & {$[217]$} \\
\hline
\end{tabular}

ACOSOG: ?; ALND: Axillary lymph node dissection; ALMANAC: ?; AMAROD-EORTC: ?; NSABP: National Surgical Adjuvant Breast and Bowel Project; RACS: ?; RT: Radiation therapy; SLN: Sentinel lymph node; SNAC: ?.

reviews; with a high success rate (97 to $98 \%$ ), a false-negative rate of $9.7 \%$ in the NSABP trial, and a significant decrease in morbidity with SLN biopsy compared with ALND [124,125].

Although SLN biopsy has become an acceptable, if not the standard, choice for determining the nodal status of clinically node-negative patients, there are still questions surrounding its use. By allowing the pathologist to thin section only one or two lymph nodes, as opposed to simply bivalving the 10-20 lymph nodes in an ALND specimen, SLN biopsy is a more accurate diagnostic test. However, this more rigorous analysis identifies patients with micrometastatic disease, particularly if immunohistochemical (IHC) staining for cytokeratin is used. This raises the predicament of whether these micrometastases are clinically relevant? With the increased use of neoadjuvant chemotherapy, the optimum timing of SLN biopsy remains in question. Finally, although ALND has in effect been replaced as a staging procedure, it is still the standard of care to complete the node dissection if the SLN is positive. Whether or not this truly impacts survival, however, remains one of the most important questions in breast cancer surgery.

\section{Micrometastases in the sentinel lymph node}

With increased scrutiny of the SLN, smaller and smaller metastases can be identified. It would seem reasonable that the discovery of any disease in the lymph node would portend a worse prognosis. However, this is not necessarily the case. Several retrospective studies have involved re-examining the lymph nodes by serial sectioning and IHC among patients who underwent negative ALND, and the outcomes of patients with occult metastases compared with those without. While some studies found a worse outcome associated with these micrometastases [126-129], most found no negative impact on prognosis [130-137].
The clinical significance of IHC-detected micrometastases is also called into question when one considers the high incidence of finding disease in patients with ductal carcinoma in situ (DCIS), which has a nearly $99 \%$ survival and for which axillary recurrences are extremely rare [138,139]. Three studies have demonstrated that IHC-detected micrometastases correlate more with the method of biopsy than with the biology of the cancer, suggesting they may be an artifact rather than a biological phenomenon [140-142]. Thus, the available evidence does not support the routine use of IHC in the evaluation of the SLN [143]. Patients with micrometastases less than $0.2 \mathrm{~mm}$ are considered node negative (current AJCC staging stages these patients as N0mic) and should not be considered for completion dissection or adjuvant chemotherapy based on their nodal status. Patients with metastases more than $0.2 \mathrm{~mm}$ should continue to be treated as node positive. Pending data from recent prospective trials will hopefully help clarify these issues.

\section{Sentinel lymph node biopsy \& neoadjuvant chemotherapy}

Prior to the introduction of sentinel lymph node biopsy as a method of staging the axilla, there was little consequence surgically on whether patients received neoadjuvant chemotherapy or not, since either way they would be receiving an axillary lymph node dissection. The most significant impact of preoperative therapy was that there were some patients who may have been node positive initially but were node negative after chemotherapy and thus their true nodal status remained unknown. This did not alter their surgery, and at the time there was less use of nodal status in guiding RT.

This changed dramatically as lymphatic mapping and Sentinel Lymph Node Biopsy (SLN) biopsy became standard in the surgical therapy of breast cancer. Now patients who opted for 
neoadjuvant chemotherapy to shrink their primary tumor were obligated to undergo ALND as part of their surgery, whereas if they had surgery first, they could opt for a sentinel node biopsy and avoid ALND if they were node negative. In addition, the nodal status plays a larger role in therapy decisions. Some medical oncologists would reserve the use of taxanes or dose-dense regimens for patients they know to be node positive. Also, the use of postmastectomy radiation for node-positive patients has become more prevalent. These practices made it more important to know prior to therapy whether the patient was node positive. Thus the question arose of how to best integrate SLN biopsy with neoadjuvant chemotherapy for clinically nodenegative breast cancer.

Sentinel node biopsy is only necessary in clinically node-negative patients. Patients with palpable disease in the lymph nodes can have this confirmed by FNA and proceed with neoadjuvant chemotherapy, with a planned ALND at the completion of systemic therapy. Clinically node-negative candidates for neoadjuvant chemotherapy should have an ultrasound of the axilla looking for abnormal lymph nodes. Ultrasoundguided FNA can then document these patients to be node positive prior to neoadjuvant chemotherapy [144,145]. For patients who are clinically and ultrasonographically node negative, there are two options for the use of SLN biopsy if they are candidates for neoadjuvant chemotherapy.

The first option is to perform the SLN biopsy prior to beginning chemotherapy [146-148]. There are several advantages to this approach. The first is that the true nodal status is known before initiating chemotherapy, which may be important if this will help decide what regimen and schedule to use. Likewise, this will help the radiation oncologist decide whether they would recommend postmastectomy radiation should the patient not become a candidate for breast conservation. For many physicians, there is increased confidence in the feasibility and accuracy of the procedure, as there has been some concern that the chemotherapy may affect the lymphatic drainage and make identification of the SLN more difficult. In addition, performing SLN biopsy after chemotherapy supposes that if there was disease in the lymph nodes, it will either completely disappear from all the nodes, or if not, it will remain in the sentinel node. However, if it is eradicated from the sentinel node but not the nonsentinel nodes, this will lead to a false negative finding. Unfortunately, performing SLN biopsy prior to the onset of chemotherapy means an extra procedure and a delay in the initiation of therapy.

The second option is to perform the SLN biopsy after completing chemotherapy [149-152]. Several studies of SLN biopsy after neoadjuvant chemotherapy have been performed and although some have suggested an unacceptably high false-negative rate, overall this seems to be reasonable [153]. While a clear disadvantage of this approach is not knowing the true pretreatment nodal status, if this would not impact the chemotherapy decisions, this is less of a factor. With regards to postmastectomy radiation, some might argue that the nodal status after chemotherapy might serve as a better indicator of whether to offer radiation to the chest wall. Delaying the SLN biopsy to after chemotherapy also allows the chemotherapy to start immediately and may preclude the need for an additional surgery. The most important advantage to SLN biopsy after chemotherapy is that patients who may have been node positive prior to chemotherapy, but are now node negative, will be spared from ALND. Approximately $20 \%$ of patients may be converted from node positive to node negative [154,155] and use of SLN biopsy prior to chemotherapy would obligate those patients to undergo ALND.

\section{The future: the end of axillary surgery in breast cancer}

What does the future hold for the regional management of breast cancer? As the strongest impetus for axillary surgery is for staging purposes, improvements in the resolution of imaging modalities may identify the presence of nodal disease without surgery. More likely, advancements in staging cancers through gene expression may preclude the need to know the regional status altogether.

\section{The need for ALND for a positive sentinel node}

Just as lumpectomy greatly minimized the morbidity of breast surgery compared with mastectomy, SLN biopsy has done the same for axillary surgery compared with ALND. As described previously, ALND may be safely avoided in the $80 \%$ of women with negative sentinel nodes. This begs the question, however, of how much benefit is added by the ALND if the SLN is positive?

Today, the standard of care in breast cancer is to perform a level I and II lymph node dissection in patients with evidence of metastatic disease in the sentinel node. Nearly half of patients with a positive SLN will have additional disease in the nonsentinel lymph nodes (NSLN) [107,156-158]. Documenting the number of involved nodes provides further staging information, which may impact adjuvant therapy decisions, as multiple involved lymph nodes is associated with increased recurrence rates and decreased survival. In many patients, however, simply knowing the patient is node positive or node negative may be enough information to determine the remainder of their therapy. In these patients, is there a therapeutic benefit to gaining regional control, or can these patients be observed, with ALND performed only if they recur?

If one could accurately predict which patients are so unlikely to harbor additional disease in the NSLN, a selective approach to completion ALND could be applied. While some clinicopathological features, such as the size and grade of the primary tumor, the size of the lymph node metastases or the ratio of positive SLN to the number of SLN removed, may help stratify risk, no factor appears sufficient to select patients who may avoid dissection [159]. Even the lowest risk groups have a $10-20 \%$ chance of harboring additional disease. While the use of statistical models or nomograms may better select patients with a low likelihood of harboring disease in the NSLN [160,161], it must be cautioned that these studies underestimate the risk of additional disease, as the NSLN are not subjected to the serial sectioning that is performed with SLN biopsy. 
Nevertheless, even if microscopic disease is left behind, this may not impact survival. As almost all patients with node positive disease will receive adjuvant systemic therapy, regional recurrence in this situation may be extremely low. But if recurrence does occur and the patient undergoes a delayed ALND, does this impact their survival? This is unknown, but as discussed, there is an increasing body of evidence that improving local control may improve survival, suggesting that failure to control regional disease may be detrimental.

The NSABP B-04 trial specifically addressed this issue, randomizing clinically node-negative patients to simple mastectomy, modified radical mastectomy or simple mastectomy with axillary radiation. After a 25 -year follow-up, there was no difference in overall survival between the three groups [162]. This is the strongest evidence against the need for ALND. However, this study had two significant flaws. First, the study was not large enough to detect a small but meaningful difference in survival. Second, many surgeons, in the habit of routinely performing modified radical mastectomies, still removed a substantial number of axillary lymph nodes when performing a simple mastectomy, clouding the results.

Other studies do suggest a benefit to regional control. A randomized trial of lumpectomy versus lumpectomy and ALND demonstrated a significantly better 5-year survival with ALND (97 vs 93\%) and a decreased incidence of distant metastases 163]. However, some of this may have been secondary to an increased use of chemotherapy based on the improved staging in the ALND arm. Two large, population-based, retrospective studies suggested a survival advantage associated with ALND compared with observation only $[164,165]$. While all retrospective data may be biased by patient selection, these findings were significant on multivariate analysis. A meta-analysis of over 3000 women involved in 6 trials randomizing patients to ALND or no ALND showed a 5\% improvement in 10-year overall survival with ALND [166]. However, much of these data are from several decades ago, and it is unclear whether the same results would be seen today given the widespread use of adjuvant systemic therapy.

While these data suggests a benefit to controling regional disease, one cannot assume that the results obtained with the omission of ALND among clinically node-negative patients from years ago would be the same as among SLN-positive patients today. Neither the risk of distant disease, nor the amount of residual disease in the axillary nodes, is directly comparable. The only way to determine whether ALND may be safely omitted for patients with a positive SLN would be a randomized trial, which was initiated by the American College of Surgeons Oncology Group (ACoSOG), but closed prematurely owing to poor accrual. Thus, the question remains unanswered, and based on our best available evidence, ALND remains the standard of care. Hopefully, future trials will provide a more definitive answer to this important oncological question.

Completion ALND is not the only option available to patients with a positive SLN. Axillary radiation may be a reasonable alternative, as evidenced by data from before the emergence of SLN biopsy. In a series of 418 women treated with axillary RT after either no or limited ALND, only $1.4 \%$ developed a regional failure after 8 years of follow-up [167]. Of the subset of patients who had a limited ALND with positive nodes, the regional failure rate was $7 \%$ (3 of 42 cases). A randomized trial in Italy of ALND versus axillary RT accrued 435 patients and, after a mean follow-up of 66 months, recorded only one axillary recurrence in the radiation arm and two in the surgery arm [168]. While these data suggest that axillary radiation may be effective in obtaining regional control, it is difficult to transpose these numbers to the SLN-positive population. A randomized trial of axillary radiation versus ALND for SLN-positive patients is presently accruing patients and will not only answer these questions, but also help determine whether axillary radiation truly decreases the morbidity of treatment compared with surgery.

\section{The need for axillary staging at all}

Although the therapeutic benefits of axillary clearance are debatable, the role of axillary staging for prognostic purposes is not, and still plays a crucial role in the management of breast cancer. However, based on the present prognostic factors (nodal status, tumor size and tumor grade), predictive factors (hormone receptors, Her2/neu) and the current recommendations for adjuvant therapy, only $10 \%$ of patients who are exposed to chemotherapy derive a benefit $[169,170]$. This is unfortunately due to the inadequacy of present markers to select out those patients who will be cured by local and regional control alone. While metastases to the lymph nodes is the most significant prognostic sign, $30 \%$ of node-negative patients will still relapse, while up to $40 \%$ of node-positive patients will be alive at 10 years [171-173]. It is clear that superior methods of predicting outcomes in breast cancer are needed.

Many additional factors have been identified as correlating with poor outcome, including angiolymphatic invasion within the primary tumor, tumor cells within the bone marrow and multiple tumor and serum markers, such as the epidermal growth factor receptor, p53, E-cadherin, Ki-67, bcl-2, cathespin $\mathrm{D}$, enhancer of zeste homolog (EZH2), cyclins and cyclindependent kinase inhibitors, and more [174-184]. While expression of these markers may correlate with outcome, their ability to further stratify patient's risk beyond size and nodal status and to reliably identify patients who may safely avoid chemotherapy, has been limited.

A more promising method of staging breast cancer patients than looking at single tumor markers is to look at the tumor genome. DNA microarray analysis uses mRNA from fresh frozen tissue to create double-stranded DNA. Using reverse transcription, amplified cRNA is labeled with fluorescent dye and hybridized to a panel of tens of thousands of genes on a chip. Computer-aided programs can then discern whether the gene is up- or down-regulated within the cancer cells. This is an extremely powerful tool that may revolutionize the management of cancer, especially breast cancer. Van't Veer and colleagues established a 70-gene profile that could reliably predict 
outcome among node-negative breast cancer patients [185,186]. While these were retrospective data, they demonstrated the potential for gene microarray analysis to accurately identify patients with different risks of recurrence despite otherwise similar appearing tumors. Other groups have pursued alternate clusters of genes to stratify risk [187-189].

One drawback to microarray analysis is the need for highquality RNA derived from fresh frozen tissue. A new technique uses reverse transcriptase polymerase chain reaction to obtain gene expression data from paraffin-embedded tissue [190]. This not only increases the clinical utility of gene expression, it allows for the testing of archived tumor samples, allowing the predictive ability of the genes to be validated. Using stored tumor samples from the NSABP B-14 trial, Paik and colleaguesl developed and validated a 21 -gene assay that could predict the likelihood of distant recurrence among ER-positive, node-negative breast cancer patients [191] and, subsequently, the benefit of adjuvant tamoxifen and chemotherapy[192]. This gene assay, known as Oncotype $\mathrm{DX}^{\circledR}$ is now available as a commercial test to help ER-positive, node negative women decide whether adjuvant chemotherapy is appropriate for them.

This represents the first step in moving from staging patients based on histopathological features to staging patients based on genomic features. Since the 21 -gene assay was developed and validated on trials limited to ER-positive, node-negative women, this is the population for whom it may be utilized. It is conceivable, however, that in the not too distant future, gene assays will be developed that can predict nodal involvement or response to therapy, regardless of tumor size or nodal status. When that time arrives, the need for SLN biopsy for staging purposes may disappear, and ALND could become an obscure operation reserved for the unusual isolated axillary recurrence.

\section{Expert commentary}

With clear evidence that local control does impact long-term survival, the focus of breast cancer treatment should not be on how much locoregional recurrence is acceptable, but rather how we can achieve optimum control while minimizing morbidity. Today, this is achieved through the appropriate use of BCT and increasing candidacy for lumpectomy through the use of neoadjuvant chemotherapy. If mastectomy is necessary, postmastectomy radiation should be used when indicated and skin-sparing mastectomies with immediate reconstruction performed when possible. The appropriate use and timing of SLN biopsy will help not only achieve regional control, but also assist in determining the most appropriate therapy for an individual patient. Navigating patients through this myriad of complex choices is the challenge for today's breast cancer specialist and highlights the benefit of, if not the need for, a multidisciplinary approach.

As new approaches and technologies become available, we must not be too hasty in adopting them based on patient preference or personal belief, but rather subject them to rigorous scientific evaluation and base our decisions on the best available clinical evidence. Letting one's mind wander, however, it is possible to envision a not too distant future where the typical breast cancer patient undergoes a core needle biopsy to provide all the necessary information on which to base treatment. Surgery is unnecessary; the tumor is ablated, possibly followed by partial breast irradiation. Targeted systemic therapy, with minimal toxicity, is then initiated only in that small percentage of patients deemed likely to benefit, based on gene expression analysis. With a continued dedication to both bench research and clinical trial design and participation, this vision may not be as far in the future as we may think.

\section{Key issues}

- After the randomized trials demonstrated no survival difference between lumpectomy alone and lumpectomy with radiation, despite a significant increase in local recurrence, many incorrectly interpreted this as 'local recurrence has no impact on survival.'

- Recent meta-analyses and randomized trials have demonstrated that improved locoregional control does indeed impact long-term survival.

- Despite the overwhelming evidence in favor of breast conservation therapy (BCT) for appropriate patients, there still exists wide variability in its application. Many patients are incorrectly thought to be poor candidates for BCT.

- Conversely, BCT is often offered to poor candidates, leading to increased local recurrence rates and possibly decreased survival.

- The use of neoadjuvant chemotherapy can increase the likelihood of breast conservation among patients who may otherwise require mastectomy.

- Postmastectomy radiation not only decreases chest wall recurrence, but may also improve survival among high-risk patients.

- Sentinel lymph node biopsy has dramatically altered the surgical staging of breast cancer, but many questions still remain regarding its most appropriate use and the role of axillary lymph node dissection for node-positive patients.

- Promising developments in both in situ ablation and partial breast irradiation may further decrease the morbidity of treatment for women with breast cancer. 


\section{References}

Papers of special note have been highlighted as:

- of interest

-• of considerable interest

1 Halsted WS. The results of operations for the cure of cancer of the breast performed at the Johns Hopkins Hospital from June, 1889-January, 1894. Johns Hopkins Hospital Bulletin 4, 1111 (1894).

2 Adair F, Berg J, Joubert L, Robbins GF. Long-term follow-up of breast cancer patients: the 30 year report. Cancer 33, 1145-1150 (1974).

3 Fisher B, Redmond C, Poisson R et al. Eightyear results of a randomized clinical trial comparing total mastectomy and lumpectomy with or without irradiation in the treatment of breast cancer. $N$. Engl. J. Med. 320(13), 822-828 (1989).

4 Fisher B, Anderson S, Bryant J et al. Twenty year follow-up of a randomized trial comparing total mastectomy, lumpectomy, and lumpectomy plus irradiation for the treatment of invasive breast cancer. N. Engl. J. Med. 347(16), 1233-1241 (2002).

5 Veronesi U, Cascinelli N, Mariani L et al. Twenty year follow-up of a randomized study comparing breast-conserving surgery with radical mastectomy for early breast cancer. $N$. Engl. J. Med. 347(16), 1227-1232 (2002).

6 Van Dongen JA, Voogd AC, Fentiman IS et al. Long-term results of a randomized trial comparing breast conserving therapy with mastectomy: European Organization for Research and Treatment of Cancer 10801 Trial. J. Natl Cancer Inst. 92, 1143-1150 (2000).

7 Poggi MM, Danforth DN, Sciuto LC et al. Eighteen year results in the treatment of early breast carcinoma with mastectomy versus breast conservation therapy: the National Cancer Institute Randomized Trial. Cancer 98, 697-702 (2003).

8 Arriagada R, MGL, Rochard F et al. Conservative treatment versus mastectomy in early breast cancer: patterns of failure with 15 years of follow-up data. Institut GustaveRoussy Breast Cancer Group. J. Clin. Oncol. 14, 1558-1564 (1996).

9 Blichert-Toft M, Rose C, Andersen JA et al. Danish randomized trial comparing breast conservation therapy with mastectomy: six years of life-table analysis. Danish Breast Cancer Cooperative Group. J. Natl Cancer Inst. Monogr. 11, 19-25 (1992).

10 Jacobson JA, Danforth DN, Cowan KH et al. Ten-year results of a comparison of conservation with mastectomy in the treatment of stage I and II breast cancer. N. Engl. J. Med. 332(14), 907-911 (1995).
11 Guadagnoli E, Weeks JC, Shapiro CL et al. Use of breast-conserving surgery for treatment of stage I and stage II breast cancer. J. Clin. Oncol. 16, 101-106 (1998).

12 Nattinger AB, Gottlieb MS, Veum J et al. Geographic variation in the use of breastconserving treatment for breast cancer. N. Engl. J. Med. 326, 1102-1107 (1992).

13 Farrow DC, Hunt WC, Samet JM. Geographic variation in the treatment of localized breast cancer. N. Engl. J. Med. 326, 1097-1101 (1992).

14 Riley GF, Potosky AL, Klabunde CN et al. Stage at diagnosis and treatment patterns among older women with breast cancer: an $\mathrm{HMO}$ and fee-for-service comparison. JAMA 281, 720-726 (1999).

15 Legorreta AP, Liu X, Parker RG. Examining the use of breast-conserving treatment for women with breast cancer in a managed care environment. Am. J. Clin. Oncol. 23, 438-441 (2000).

16 Hiotis K, Ye W, Sposto R, Skinner KA. Predictors of breast conservation therapy: size is not all that matters. Cancer 103 , 892-899 (2005).

17 Locker GY, Sainsbury JR, Cuzick J, Group AT. Breast surgery in the 'Arimidex, Tamoxifen Alone or in Combination' (ATAC) trial: American women are more likely than women from the United Kingdom to undergo mastectomy. Cancer 101(4), 735-40 (2004).

18 Simmons RM, Adamovich TL. Skin-sparing mastectomy. Surg. Clin. North Am. 83, 885-899 (2003).

19 Cocquyt VF, Blondeel PN, Depypere HT et al. Better cosmetic results and comparable quality of life after skin-sparing mastectomy and immediate autologous breast reconstruction compared to breast conservative treatment. Br. J. Plast. Surg. 56, 462-470 (2003).

20 Downes KJ, Glatt BS, Kanchwala SK et al. Skin-sparing mastectomy and immediate reconstruction is an acceptable treatment option for patients with high-risk breast carcinoma. Cancer 103, 906-913 (2005).

21 Foster RD, Esserman LJ, Anthony JP et al. Skin-sparing mastectomy and immediate breast reconstruction: a prospective cohort study for the treatment of advanced stages of breast carcinoma. Ann. Surg. Oncol. 9, 462-466 (2002).

22 Chagpar AB, Studts JL, Scoggins CR et al. Factors associated with surgical options for breast carcinoma. Cancer 106(7), 1462-1466 (2006).

- Study eliciting some of the patient and physician factors that impact a patient's decision to pursue breast conservation versus mastectomy.

23 Katz SJ, Lantz PM, Janz NK et al. Surgeon perspectives about local therapy for breast carcinoma. Cancer 104(9), 1854-1861 (2005).

24 Katz SJ, Lantz PM, Janz NK et al. Patient involvement in surgery treatment decisions for breast cancer. J. Clin. Oncol. 23(24), 5526-5533 (2005).

25 Lantz PM, Janz NK, Fagerlin A et al. Satisfaction with surgery outcomes and the decision process in a population-based sample of women with breast cancer. Health Services Res. 40(3), 745-767 (2005).

26 Janz NK, Wren PA, Copeland LA et al. Patient-physician concordance: preference, perceptions, and factors influencing the breast cancer surgical decision. J. Clin. Oncol. 22(15), 3091-3098 (2004).

27 Whelan T, Levine M, Willan A et al. Effect of a decision aid on knowledge and treatment decision making for breast cancer surgery: a randomized trial. JAMA 292(4), 435-441 (2004).

28 Morrow M, Strom EA, Bassett LW et al. Standard for breast conservation therapy in the management of invasive breast carcinoma. CA Cancer J. Clin. 52, 277-300 (2002).

- Review of which patients are appropriate candidates for breast conserving therapy and which patients are better served by mastectomy.

29 Fleck R, McNeese MD, Ellerbroek NA et al. Consequences of breast irradiation in patients with pre-existing collagen vascular diseases.

Int. J. Radiat. Oncol. Biol. Phys. 17, 829-833 (1989).

30 Morris MM, Powell SN. Irradiation in the setting of collagen vascular disease: acute and late complications. J. Clin. Oncol. 15, 2728-2735 (1997).

31 Ross JG, Hussey DH, Mayr NA, Davis CS. Acute and late reactions to radiation therapy in patients with collagen vascular diseases. Cancer 71, 3744-3752 (1993).

32 Wilson LD, Beinfield M, McKhann CF, Haffty BG. Conservative surgery and radiation in the treatment of synchronous ipsilateral breast cancers. Cancer 72, 137-142 (1993).

33 Leopold KA, Recht A, Schnitt SJ et al. Results of conservative surgery and radiation therapy for multiple synchronous cancers of one breast. Int. J. Radiat. Oncol. Biol. Phys. 16, 11-16 (1989).

34 Kurtz JM, Jacquemier J, Amalric R et al. Breast-conserving therapy for macroscopically multiple cancers. Ann. Surg. 212, 38-44 (1990). 
35 Cho LC, Senzer N, Peters GN.

Conservative surgery and radiation therapy for macroscopically multiple ipsilateral invasive breast cancers. Am. J. Surg. 183, 650-654 (2002).

36 Staradub VL, Hsieh Y-C, Clauson J et al. Factors that influence surgical choices in women with breast carcinoma. Cancer 95(6), 1185-1190 (2002).

37 Gage I, Recht A, Gelman RS et al. Long-term outcome following breastconserving surgery and radiation therapy. Int. J. Radiat. Oncol. Biol. Phys. 33(2), (1998).

38 Nixon AJ, Newberg D, Hayes DF et al. Relationship of patient age to pathologic features of the tumor and prognosis for patients with stage I or II breast cancer. J. Clin. Oncol. 12, 888-94 (1994).

39 Kurtz JM, Jacquemier J, Amalric R et al. Why are local recurrences after breastconserving therapy more frequent in younger patients? J. Clin. Oncol. 8 , 591-598 (1990)

40 Pierce LJ, Strawderman M, Narod SA et al. Effect of radiotherapy after breast conserving treatment in women with breast cancer and germline BRCA $1 / 2$ mutations. J. Clin. Oncol. 18, 3360-3369 (2000).

41 Pierce LJ, Levin AM, Rebbeck TR et al. Ten-year multi-institutional results of breast conserving surgery and radiotherapy in BRCA1/2-associated stage I/II breast cancer. J. Clin. Oncol. 24(16), 2437-2443 (2006).

42 Schwartz GF, Hortobagyi GN. Proceedings of the consensus conference on neoadjuvant chemotherapy in carcinoma of the breast, April 26-28, 2003, Philadelphia,

Pennsylvania. Cancer 100(12), 2512-2532 (2004).

43 Fisher B, Brown A, Mamounas E et al. Effect of preoperative chemotherapy on local-regional disease in women with operable breast cancer: Findings from National Surgical Adjuvant Breast and Bowel Project B-18. J. Clin. Oncol. 15(7), 2483-2493 (1997).

44 Ghafoor A, Jemal A, Ward E et al. Trends in breast cancer by race and ethnicity. CA Cancer J. Clin. 53, 342-355 (2003).

45 Kaufman CS, Bachman B, Littrup PJ et al. Cryoablation treatment of benign breast lesions with 12-month follow-up. Am. J. Surg. 188, 340-348 (2004).

46 Tafra L, Smith JS, Woodward JE et al. Pilot study of cryo-assisted lumpectomy for small ultrasound visible breast cancers (abstract). Ann. Surg. Oncol. 10(Suppl. 1), S33-S34 (2003).
47 Staren ED, Sabel MS, Gianakakis LM et al. Cryosurgery of breast cancer. Arch. Surg. 132(1), 28-33 (1997).

48 Sabel MS, Kaufman CS, Whitworth P et al. Cryoablation of early-stage breast cancer: Work-in-progress report of a multiinstitutional trial. Ann. Surg. Oncol. 11, 542-549 (2003).

49 Pfleiderer SO, Freesmeyer MG, Marx C et al. Cryotherapy of breast cancer under ultrasound guidance: initial results and limitations. Eur. Radiol. 12(12), 3009-3014 (2002).

50 Morin J, Traore' A, Dionne G et al. Magnetic-resonance-guided percutaneous cryosurgery of breast carcinoma: technique and early clinical results. Can. J. Surg. 47(5), 347-351 (2004).

51 Sabel MS, Nehs MA, Su G et al. Immunologic response to cryoablation of breast cancer. Breast Cancer Res. Treat. 90, 97-104 (2005).

52 Fornage BC, Sneige N, Ross MI et al. Small $(<2 \mathrm{~cm})$ breast cancer treated with USguided radiofrequency ablation: Feasibility study. Radiology 231, 215-224 (2004).

53 Izzo F, Thomas R, Delrio P et al. Radiofrequency ablation in patients with primary breast carcinoma. A pilot study in 26 patients. Cancer 92, 2036-2044 (2001).

54 Hayasi A, Silver SF, van der Westhuizen NG. Treatment of invasive breast carcinoma with ultrasound guided radiofrequency ablation. Am. J. Surg. 185, 429-435 (2003).

55 Singletary SE. Feasibility of radiofrequency ablation for primary breast cancer. Breast Cancer 10, 4-9 (2003).

56 Burak WE, Angese MA, Povoski SP et al. Radiofrequency ablation of invasive breast carcinoma followed by delated surgical excision. Cancer 98, 1369-1376 (2003).

57 Dowlatshahi K, Fan M, Gould VE et al. Stereotactically guided laser therapy of occult breast tumors: Work in progress report. Arch. Surg. 135, 1345-1352 (2000).

58 Dowlatshahi K, Francescatti DS, Bloom KJ. Laser therapy for small breast cancers. Am. J. Surg. 184, 359-363 (2002)

59 Harms SE, Klimberg VS, Henry-Tilman R et al. MRI directed laser therapy for benign and malignant breast neoplasms: Clinical follow-up and histologic correlation (abstract). Radiological Society of North America Annual Meeting (2000).

60 Mumtaz H, Hall-Graggs MA, Wotherspoon A et al. Laser therapy for breast cancer: MR imaging and histopathologic correlation. Radiology 200, 651-658 (1996).
61 Robinson DS, Parel J-M, Denham DB et al. Interstitial laser hyperthermia model development for minimally invasive therapy of breast carcinoma. J. Am. Coll. Surg. 186(3), 284-292 (1998).

62 Fenn AJ, Wolf GL, Fogle RM. An adaptive microwave phased array for targeted heating of deep tumours in intact breast: animal study results. Int. J. Hyperthermia 15(1), 45-61 (1999).

63 Gardner RA, Vargas HI, Block JB et al. Focused microwave phased array thermotherapy for primary breast cancer. Ann. Surg. Oncol. 9(4), 326-332 (2002).

64 Vargas HI, Dooley WC, Gardner RA et al. Focused microwave phases array thermotherapy for ablation of early-stage breast cancer: Results of thermal dose escalation. Ann. Surg. Oncol. 11, 139-146 (2004).

65 Huber PE, Jenne JW, Rastert R et al. A new non-invasive approach in breast cancer therapy using magnetic resonance imaging guided focused ultrasound surgery. Cancer Res. 61, 8441-8447 (2001).

66 Gianfelice D, Khiat A, Amara M et al. Imaging-guided focused US ablation of breast cancer: histopathologic assessment of effectiveness - initial experience. Radiology 227, 849-855 (2003).

67 Clarke M, Collins R, Darby S et al. Effects of radiotherapy and of differences in the extent of surgery for early breast cancer on local recurrence and 15 year survival: an overview of the randomized trials. Lancet 366(9503), 2087-2106 (2005).

-• Meta-analysis of 78 randomized trials involving 42,000 women demonstrating that the avoidance of a local recurrence would impact breast cancer mortality.

68 Whelan TJ, Julian J, Wright J et al. Does locoregional radiation therapy improve survival in breast cancer? A meta-analysis. J. Clin. Oncol. 18, 1220-1229 (2000).

- Systematic review of 18 randomized trials involving over 6,000 patients demonstrating a reduction in mortality among patients who received locoregional radiation.

69 Schnitt SJ, Hayman JA, Gelman RS et al. A prospective study of conservative surgery alone in the treatment of selected patients with stage I breast cancer. Cancer 77, 1094-1100 (1996).

70 Fisher B, Bryant J, Dignam JJ et al. Tamoxifen, radiation therapy, or both for prevention of ipsilateral breast tumor recurrence after lumpectomy in women with invasive breast cancers of one centimeter or less. J. Clin. Oncol. 20, 4141-4149 (2002). 
71 Nemoto T, Patel JK, Rosner D et al. Factors affecting recurrence in lumpectomy without irradiation for breast cancer. Cancer 67, 2079-2082 (1991).

72 Kantorowitz DA, Poulter CA, Sischy B et al. Treatment of breast cancer among elderly women with segmental mastectomy or segmental mastectomy plus postoperative radiotherapy. Int. J. Radiat. Oncol. Biol. Phys. 15, 263-270 (1988).

73 Reed MW, Morrison JM. Wide local excision as the sole primary treatment in elderly patients with carcinoma of the breast. Br. J. Surg. 76, 898-900 (1989).

74 Fyles AW, McCready DR, Manchul LA et al. Tamoxifen with or without breast irradiation in women 50 years of age or older with early breast cancer. $N$. Engl. J. Med. 351, 963-970 (2004).

75 Hughes KS, Schnaper LA, Berry D et al. Lumpectomy plus tamoxifen with or without irradiation in women 70 years of age or older with early breast cancer. N. Engl. J. Med. 351(10), 971-977 (2004).

76 Recht A, Gray R, Davidson NE et al. Locoregional failure 10 years after mastectomy and adjuvant chemotherapy with or without tamoxifen without irradiation: experience of the Eastern Cooperative Oncology Group. J. Clin. Oncol. 17, 1689-1700 (1999).

77 Taghian A, Jeong JH, Mamounas E et al. Patterns of locoregional failure in patients with operable breast cancer treated by mastectomy and adjuvant chemotherapy with or without tamoxifen and without radiotherapy: results from five National Surgical Adjuvant Breast and Bowel Project randomized clinical trials. J. Clin. Oncol. 22, 4247-4254 (2004).

78 Katz A, Strom EA, Buchholz TA et al. Locoregional recurrence patterns after mastectomy and doxorubicin-based chemotherapy: Implications for postoperative irradiation. J. Clin. Oncol. 18, 2817-2827 (2000).

79 Fowble B, Gray R, Gilchrist K et al. Identification of a subgroup of patients with breast cancer and histologically positive axillary nodes receiving adjuvant chemotherapy who may benefit from postoperative radiotherapy. J. Clin. Oncol. 6, 1107-1117 (1988).

80 Stjernsward J. Decreased survival related to irradiation postoperatively in early operable breast cancer. Lancet 2 , 1285-1286 (1974).

81 Overgaard M, Hansen PS, Overgaard J et al. Postoperative radiotherapy in highrisk premenopausal women with breast cancer who receive adjuvant therapy. Danish Breast Cancer Cooperative Group 82b Trial. N. Engl. J. Med. 337, 949-955 (1997).

82 Recht A, Houlihan MJ. Axillary lymph nodes and breast cancer: a review. Cancer 76, 1491-1512 (1995).

83 Ragaz J, Jackson SM, Le N et al. Adjuvant radiotherapy and chemotherapy in nodepositive premenopausal women with breast cancer. N. Engl. J. Med. 337, 956-962 (1997).

84 Ragaz J, Olivotto IA, Spinelli JJ et al. Locoregional radiation therapy in patients with high-risk breast cancer receiving adjuvant chemotherapy: 20 year results of the British Columbia randomized trial. J. Natl Canc. Inst. 97(2), 116-126 (2005).

85 Overgaard M, Jensen MB, Overgaard J et al. Postoperative radiotherapy in highrisk postmenopausal breast-cancer patients given adjuvant tamoxifen: Danish Breast Cancer Cooperative Group DBCG 82c randomised trial. Lancet 353, 1641-1648 (1999).

86 Recht A, Edge SB, Solin LJ et al. Postmastectomy radiotherapy: clinical practice guidelines of the American Society of Clinical Oncology. J. Clin. Oncol. 19, 1539-1569 (2001).

87 Schecter NR, Strom EA, Perkins GH et al. Immediate breast reconstruction can impact postmastectomy irradiation. Am. J. Clin. Oncol. 28(5), 485-494 (2005).

88 Kronowitz SJ, Hunt KK, Keurer HM et al. Delayed-immediate breast reconstruction. Plastic Reconstructive Surg. 113, 1617-1628 (2004).

89 Holland R, Veling SH, Mravunac M et al. Histologic multifocality of Tis, T1-2 breast carcinomas. Implications for clinical trials of breast-conserving surgery. Cancer 56, 979-990 (1985).

90 Harris JR. Notes on the Ontario trial in the context of breast-conserving therapy for early-stage breast cancer. J. Clin. Oncol. 18, 43S-44S (2000).

91 Whelan TJ, MacKenzie RG, Levine M et al. A randomized trial comparing two fractionation schedules for breast irradiation postlumpectomy in nodenegative breast cancer (abstract). Proc. Am. Soc. Clin. Oncol. 19, 2A (2000).

92 Fortin A, Larochelle M, Laverdiere J et al. Local failure is responsible for the decrease in survival for patients wtih breast cancer treated with conservative surgery and postoperative radiotherapy. J. Clin. Oncol. 17, 101-109 (1999).
93 Boyages J, Recht A, Connolly JL et al. Early breast cancer: predictors of breast recurrence for patients treated with conservative surgery and radiation therapy. Radiother. Oncol. 19, 29-41 (1990).

94 Liljegren G, Holmberg L, Bergh J et al. 10 year results after sector resection with or without postoperative radiotherapy for stage I breast cancer: a randomized trial. J. Clin. Oncol. 17, 2326-2333 (1999).

95 Touboul E, Buffat L, Belkacemi Y et al. Local recurrences and distant metastases after breast-conserving surgery and radiation therapy for early breast cancer. Int. J. Radiat. Oncol. Biol. Phys. 43, 25-38 (1999).

96 Smith TE, Lee D, Turner BC et al. True recurrence vs. new primary ipsilateral breast tumor relapse: an analysis of clinical and pathologic differences and their implications in natural history, prognoses, and therapeutic management. Int. J. Radiat. Oncol. Biol. Phys. 48, 1281-1289 (2000).

97 Huang E, Buchholz TA, Meric F et al. Classifying local disease recurrences after breast conservation therapy based on location and histology: new primary tumors have more favorable outcomes than true local disease recurrences. Cancer 95, 2059-2067 (2002).

98 Pawlik TM, Buchholz TA, Kuerer HM. The biologic rationale for and emerging role of accelerated partial breast irradiation for breast cancer. JACS 199(3), 480-492 (2004).

99 Keisch M, Vicini FA, Kuske RR et al. Initial clinical experience with the MammoSite breast brachytherapy applicator in women with early-stage breast cancer treated with breast conserving therapy. Int. J. Radiat. Oncol. Biol. Phys. 55, 289-293 (2003).

100 Vicini FA, Beitsch PD, Quiet CA et al. First analysis of patient demographics, technical reproducibility, cosmesis and early toxicity. Cancer 104, 1138-1148 (2005).

101 Krueger EA, Fraass BA, Pierce LJ. Clinical aspects of intensity-modulated radiotherapy in the treatment of breast cancer. Semin. Radiat. Oncol. 12, 250-259 (2002).

102 Strom EA. Breast IMRT: new tools leading to new vision. Int. J. Radiat. Oncol. Biol. Phys. 54, 1297-1298 (2002).

103 Vicini FA, Sharpe M, Kestin L et al. Optimizing breast cancer treatment efficacy with intensity-modulated radiotherapy. Int J. Radiat. Oncol. Biol. Phys. 54, 1336-1344 (2002).

104 Vaidya JS, Tobias JS, Baum M et al. Intraoperative radiotherapy for breast cancer. Lancet Oncol. 5, 165-173 (2004). 
105 Tobias JS, Vaidya JS, Keshgart M et al. Reducing radiotherapy dose in early breast cancer: The concept of conformal intraoperative brachytherapy. Br. J. Radiol. 77, 279-284 (2004).

106 Veronesi U, Gatti G, Luini A et al. Full-dose intraoperative radiotherapy with electrons during breast conservation surgery. Arch. Surg. 138, 1253-1256 (2003).

107 Krag D, Weaver D, Ashikaga T et al. The sentinel node in breast cancer - a multicenter validation study. $N$. Engl. J. Med. 339, 941-946 (1998).

108 Guiliano AE, Jones RC, Brennan M, Statman R. Sentinel lymphadenectomy in breast cancer. J. Clin. Oncol. 15, 2345-2350 (1997).

109 Guiliano AE, Dale PS, Turner RR et al. Improved staging of breast cancer with sentinel lymphadenectomy. Ann. Surg. 3, 394-401 (1995).

110 Veronesi U, Paganelli G, Galimberti V et al. Sentinel node biopsy to avoid axillary dissection in breast cancer with clinically negative lymph nodes. Lancet 349 , 1864-1867 (1997).

111 Cody HS, Fey JV, Akhurst T et al. Complementarity of blue dye and isotope in sentinel node localization for breast cancer: univariate and multivariate analysis of 966 procedures. Ann. Surg. Oncol. 8, 13-19 (2001).

112 McMasters KM, Tuttle TM, Carlson DJ et al. Sentinel lymph node biopsy for breast cancer: a suitable alternative to routine axillary dissection in multi-institutional practice when optimal technique is used. J. Clin. Oncol. 18, 2560-2566 (2000).

113 Naik AM, Fey JV, Gemignani ML et al. The risk of axillary relapse after sentinel lymph node biopsy for breast cancer is comparable with that of axillary lymph node dissection: a follow-up study of 4008 procedures. Ann. Surg. 240, 462-471 (2004)

114 Swenson KK, Mahipal A, Nissen MJ et al. Axillary disease recurrence after sentinel lymph node dissection for breast carcinoma. Cancer 104, 1834-1839 (2005).

115 Giuliano AE, Haigh PI, Brennan MB et al. Prospective observational study of sentinel lymphadenectomy without further axillary dissection in patients with sentinel nodenegative breast cancer. J. Clin. Oncol. 18, 2553-2559 (2000).

116 Cox CE, Bass SS, McCann CR et al. Lymphatic mapping and sentinel lymph node biopsy in patients with breast cancer. Annu. Rev. Med. 51, 525-42 (2000).
117 Fraile M, Rull M, Julian FJ et al. Sentinel node biopsy as a practical alternative to axillary lymph node dissection in breast cancer patients: an approach to its validity. Ann. Oncol. 11, 701-705 (2000).

118 Lyman GH, Kim TY, Giuliano AE. A systematic review and meta-analysis of lymphatic mapping and sentinel node biopsy (SNB) in early stage breast cancer (Abstract 2001). San Antonio Breast Conference. San Antonio, TX, USA (2004).

119 Allweis TM, Badriyyah M, Bar Ad V et al. Current controversies in sentinel lymph node biopsy for breast cancer. Breast 12(3), 163-171 (2003).

120 Sanidas EE, Deskalakis M, Sbyrakis N, Tsiftsis DD. Modifications of the learning curve guidelines for breast cancer sentinel node biopsy. Eur. J. Cancer 31(4), 357-363 (2005).

121 Cochran AJ, Roberts AA, Saida T. The place of lymphatic mapping and sentinel node biopsy in oncology. Int. J. Clin. Oncol. 8(3), 139-150 (2003).

122 Sanidas EE, de Bree E, Tsiftsis DD. How many cases are enough for accreditation in sentinel lymph node biopsy in breast cancer? Am. J. Surg. 185(3), 202-210 (2003).

123 Veronesi U, Paganelli G, Viale G et al. A randomized comparison of sentinel-node biopsy with routine axillary dissection in breast cancer. N. Engl. J. Med. 349, 546-553 (2003).

124 Julian TB, Krag DN, Brown A et al. Preliminary technical results of NSABP B-32, a randomized phase III clinical trial to compare sentinel node resection to conventional axillary dissection in clinically node-negative breast cancer patients (Abstract). San Antonio Breast Cancer Symposium. San Antonio, TX, (2004).

125 Mansel RE, Goyal A, Fallowfield L et al. Sentinel node biopsy versus standard axillary treatment: results of the randomized multicenter UK ALMANAC trial (Abstract). San Antonio Breast Cancer Symposium. San Antonio, TX, (2004).

126 International (Ludwig) Breast Cancer Study Group. Prognostic importance of occult axillary lymph node micrometastases from breast cancers. Lancet 335, 1565 (1990).

127 Hainsworth PJ, Tjandra JJ, Stillwell RG et al. Detection and significance of occult metastases in node-negative breast cancer. $\mathrm{Br}$. J. Surg. 80, 459-463 (1993).

128 McGuckin MA, Cummings MC, Walsh MD et al. Occult axillary node metastases in breast cancer: their detection and prognostic significance. Br. J. Cancer 73 , 88-95 (1996).
129 Clare SE, Sener SF, Wilkens W et al. Prognostic significance of occult lymph node metastases in node-negative breast cancer. Ann. Surg. Oncol. 4, 447 (1997).

130 Cote RJ, Peterson HF, Chaiwun B et al. Role of immunohistochemical detection of lymph-node micrometastases in management of breast cancer. International Breast Cancer Study Group. Lancet 354, 896 (1999).

131 Pickren JW. Significance of occult metastases. A study of breast cancer. Cancer 14, 1266-1271 (1961).

132 Fisher ER, Swamidoss S, Lee CH et al. Detection and significance of occult axillary node metastases in patients with invasive breast cancer. Cancer 42, 2025-2031 (1978).

133 Rosen PP, Saigo PE, Braun DW et al. Occult axillary lymph node metastases from breast cancers with intramammary lymphatic tumor emboli. Am. J. Surg. Pathol. 6, 639-641 (1982).

134 Wilkinson EJ, Hause LL, Hoffman RG et al. Occult axillary lymph node metastases in invasive breast carcinoma: characteristics of the primary tumor and significance of the metastases. Pathol. Annu. 17(Pt 2), 67-91 (1982).

135 de Mascarel I, MacGrogan G, Picot V, Mathoulin-Pelissier S. Prognostic significance of immunohistochemically detected breast cancer node metastases in 218 patients. Br. J. Cancer 87, 70-74 (2002).

136 Chagpar AB, Middleton LP, Sahin AA et al. Clinical outcome of patients with lymph node-negative breast carcinoma who have sentinel lymph node micrometastases detected by immunohistochemistry. Cancer 103(8), 1571-1580 (2005).

137 Langer I, Marti WR, Guller U et al. Axillary recurrence rate in breast cancer patients wtih negative sentinel lymph node (SLN) or SLN micrometastases: prospective analysis of 150 patients after SLN biopsy. Ann. Surg. 241, 152-158 (2005).

138 Klauber-DeMore N, Tan LK, Liberman L et al. Sentinel lymph node biopsy: is it indicated in patients with high-risk ductal carcinoma in situ and ductal carcinoma in situ with microinvasion? Ann. Surg. Oncol. 7(9), 636-642 (2000).

139 Edge SB, Sheldon DG. Sentinel lymph node biopsy is not indicated for ductal carcinoma in situ. J. Natl Comprehensive Cancer Network 1(2), 207-212 (2003).

140 Hansen NM, Ye X, Grube BJ, Guiliano AE. Manipulation of the primary breast tumor and the incidence of sentinel node metastases from invasive breast cancer. Arch. Surg. 139, 634-640 (2004). 
141 Newman EL, Kahn A, Diehl KM et al. Does the method of biopsy affect the incidence of sentinel lymph node metastases? Breast J. 12(1), 53-57 (2006).

142 Moore KH, Thaler HT, Tan LK et al. Immunohistochemically detected tumor cells in the sentinel lymph nodes of patients with breast carcinoma. Biologic metastasis or procedural artifact? Cancer 100 , 929-934 (2004).

143 Lyman GH, Guiliano AE, Somerfield MR et al. American Society of Clinical Oncology guideline recommendations for sentinel lymph node biopsy in early-stage breast cancer. J. Clin. Oncol. 23, 7703-7720 (2005).

144 van Rijk MC, Deurloo EE, Nieweg OE et al. Ultrasonography and fine-needle aspiration cytology can spare breast cancer patients unnecessary sentinel lymph node biopsy. Ann. Surg. Oncol. 13(1), 31-35 (2006).

145 Khan A, Sabel MS, Nees A et al. Comprehensive axillary evaluation in neoadjuvant chemotherapy patients with ultrasonography and sentinel lymph node biopsy. Ann. Surg. Oncol. 12(9), 697-704 (2005).

146 Sabel MS, Schott AF, Kleer CG et al. Sentinel node biopsy prior to neoadjuvant chemotherapy. Am. J. Surg. 186(2), 102-105 (2003).

147 Jones JL, Zabicki K, Christian RL et al. A comparison of sentinel node biopsy before and after neoadjuvant chemotherapy: timing is important. Am. J. Surg. 190(4), 517-520 (2005).

148 Schrenk P, Hochreiner G, Fridrik M, Wayand W. Sentinel node biopsy performed before preoperative chemotherapy for axillary lymph node staging in breast cancer. Breast Journal 9(4), 282-287 (2003).

149 Breslin TM, Cohen LF, Sahin AA et al. Sentinel lymph node biopsy is accurate after neoadjuvant chemotherapy for breast cancer. J. Clin. Oncol. 18(20), 3480-3486 (2000).

150 Brady EW. Sentinel lymph node mapping following neoadjuvant chemotherapy for breast cancer. Breast J. 8(2), 97-100 (2002).

151 Mamounas EP, Brown A, Smith R et al. Accuracy of sentinel node biopsy after neoadjuvant chemotherapy in breast cancer: updated results from NSABP B-27. Proc. Am. Soc.Clin. Oncol. 21, 140 (2002).

152 Stearns V, Ewing CA, Slack R et al. Sentinel lymphadenectomy after neoadjuvant chemotherapy for breast cancer may reliably represent the axilla except for inflammatory breast cancer. Ann. Surg. Oncol. 9(3), 235-242 (2002).

153 Xing Y, Foy M, Cox DD et al. Meta-analysis of sentinel lymph node biopsy after preoperative chemotherapy in patients with breast cancer. Br. J. Surg. 93, 539-546 (2006).

154 Keuerer HM, Sahin AA, Hunt KK et al. Incidence and impact of documented eradication of breast cancer axillary lymph node metastases prior to surgery in patients treated with neoadjuvant chemotherapy. Ann. Surg. 230, 72-78 (1999).

155 Hennessy BT, Hortobagyi GN, Rouzier R et al. Outcome after pathologic complete eradication of cytologically proven breast cancer axillary node metastases following primary chemotherapy. J. Clin. Oncol. 23(36), 9304-9311 (2005).

156 Guiliano AE, Kirgan DM, Guenther JM et al. Lymphatic mapping and sentinel lymphadenectomy for breast cancer. Ann. Surg. 220, 391-401 (1994).

157 Borgstein PJ, Pijpers R, Comans EF et al. Sentinel lymph node biopsy in breast cancer: guidelines and pitfalls of lymphoscintigraphy and $\gamma$ probe detection. J. Am. Coll. Surg. 186, 275-283 (1998).

158 Albertini JJ, Lyman GH, Cox CE et al. Lymphatic mapping and sentinel node biopsy in the patient with breast cancer. JAMA 276, 1818-1822 (1996).

159 Degnim AC, Griffith KA, Sabel MS et al. Clinicopathologic features of metastasis in nonsentinel lymph nodes of breast carcinoma patients. Cancer 98(11), 2307-2315 (2003).

160 Van Zee KJ, Manasseh DM, Bevilacqua JL et al. A nomogram for predicting the likelihood of additional nodal metastases in breast cancer patients with a positive sentinel node biopsy. Ann. Surg. Oncol. 10, 1140-1151 (2003).

161 Degnim AC, Reynolds C, Pantvaidya G et al. Nonsentinel node metastasis in breast cancer patients: assessment of an existing and a new predictive nomogram. Am. J. Surg. 190(4), 543-550 (2005).

162 Fisher B, Jeong J-H, Anderson S et al. Twenty-five year follow-up of a randomized trial comparing radical mastectomy, total mastectomy and total mastectomy followed by irradiation. N. Engl. J. Med. 347, 567-575 (2002).

163 Cabanes PA, Salmon RJ, Vilcoq JR et al. Value of axillary dissection in addition to lumpectomy and radiotherapy in early breast cancer. The Breast Carcinoma Collaborative Group of the Institut Curie. Lancet 339(8804), 1245-1248 (1992).
164 Truong PT, Bernstein V, Wai E et al. Ag-related variations in the use of axillary dissection: a survival analysis of 8038 women with T1-ST2 breast cancer. Int. J. Radiat. Oncol. Biol. Phys. 54(3), 794-803 (2002).

165 Joslyn SA, Konety BR. Effect of axillary lymphadenectomy on breast carcinoma survival. Breast Cancer Res. Treat. 91(1), 11-18 (2005).

166 Orr RK. The impact of prophylactic axillary node dissection on breast cancer survival--a Bayesian meta-analysis. Ann. Surg. Oncol. 6(1), 109-116 (1999).

167 Galper S, Recht A, Silver B et al. Is radiation alone adequate treatment to the axilla for patients with limited axillary surgery? Implications for treatment after a positive sentinel node biopsy. Int. J. Radiat. Oncol. Biol. Phys. 48(1), 125-132 (2000).

168 Zurrida S, Orecchia R, Galimberti V et al. Axillary radiotherapy instead of axillary dissection: a randomized trial. Italian Oncological Senology Group. Ann. Surg. Oncol. 9, 117-119 (2002).

169 Goldhirsch A, Glick JH, Gelber RD et al. International consensus panel on the treatment of primary breast cancer. Seventh international conference on adjuvant therapy of primary breast cancer. J. Clin. Oncol. 19, 3817-3827 (2001).

170 Eifel P, Axelson JA, Costa J et al. National Institutes of Health Consensus Development Conference Statement: adjuvant therapy for breast cancer, November 1-3, 2000. J. Natl Canc. Inst. 93, 979-989 (2001).

171 Early BreastCancerTrialists Collaborative Group. Systemic treatment of early breast cancer by hormonal, cytotoxic or immune therapy. Lancet 339, 1-15 (1992).

172 Fisher B, Redmond C, Dimitrov NV et al. A randomized clinical trial evaluating sequential methotrexate and flourouracil in the treatment of patients with nodenegative breast cancer who have estrogen receptor negative tumors. $N$. Engl. J. Med. 320, 473-478 (1989).

173 Mansour EG, Gray R, Shatila AH et al. Survival advantage of adjuvant chemotherapy in high-risk node-negative breast cancer: ten year analysis - an intergroup study. J. Clin. Oncol. 16, 3486-3492 (1998).

174 Beenken SW, Grizzle WE, Crowe DR et al. Molecular biomarkers for breast cancer prognosis: coexpression of c-erbB-2 and p53. Ann. Surg. 233, 630-638 (2001). 
175 Hayes DF, Isaacs C, Stearns V. Prognostic factors in breast cancer: current and new predictors of metastasis. J. Mammary Gland Biol. Neoplasia 6(4), 375-392 (2001).

176 Kleer CG, Cao Q, Varambally S et al. $\mathrm{EZH} 2$ is a marker of aggressive breast cancer and promotes neoplastic transformation of breast epithelial cells. Proc. Natl Acad. Sci. USA 100(20), 11606-11611 (2003).

177 Davis BW, Gelber RD, Goldhirsch A et al. Prognostic significance of peritomral vessel invasion in clinical trials of adjuvant therapy for breast cancer with axillary lymph node metastases. Hum. Pathol. 16, 1212-1218 (1985).

178 Woo CS, Silberman H, Nakamura SK et al. Lymph node status combined with lymphovascular invasion creates a more powerful tool for predicting outcome in patients with invasive breast cancer. Am. J. Surg. 184, 337-340 (2002).

179 Pharoah PD, Day NE, Caldas C. Somatic mutations in the $\mathrm{p} 53$ gene and prognosis in breast cancer: a meta-analysis. Br. J. Cancer 80, 1968-1973 (1999).

180 Bull SB, Ozcelik H, Pinnaduwage D et al. The combination of $\mathrm{p} 53$ mutation and neu/erbB-2 amplification is associated with poor survival in node-negative breast cancer. J. Clin. Oncol. 22, 86-96 (2004).

181 Porter PL, Malone KE, Heagerty PJ et al. Expression of cell-cycle regulators p27Kip1 and cyclin $\mathrm{E}$, alone and in combination, correlate with survival in young breast cancer patients. Nat. Med. 3, 222-225 (1997).

182 Keyomarsi K, Tucker SL, Buchholz TA et al. Cyclin $\mathrm{E}$ and survival in patients with breast cancer. N. Engl. J. Med. 347(20), 1566-1575 (2002).

183 Barnes DM, Gillett CE. Cyclin D1 in breast cancer. Breast Cancer Res. Treat. 52, 1-15 (1998).

184 Braun S, Pantel K, Muller P et al. Cytokeratin-positive cells in the bone marrow and survival of patients with stage I, II or III breast cancer. N. Engl. J. Med. 342, 525-533 (2000).

185 van't Veer LJ, Dai H, van de Vijver MJ et al. Gene expression profiling predicts clinical outcome of breast cancer. Nature 415, 530-536 (2002).

186 van de Vijver MJ, He YD, van't Veer LJ et al. A gene-expression signature as a predictor of survival in breast cancer. N. Engl. J. Med. 347, 1999-2009 (2002).

187 Ahr A, Karn T, Solbach C et al. Identification of high risk breast-cancer patients by gene expression profiling. Lancet 359, 131-132 (2002).
188 West M, Blanchette C, Dressman $\mathrm{H}$ et al. Predicting the clinical status of human breast cancer by using gene expression profiles. Proc. Natl Acad. Sci. USA 98(20), 11462-11467 (2001).

189 Sorlie T, Perou CM, Tibshirani R et al. Gene expression patterns of breast carcinomas distinguish tumor subclasses with clinical implications. Proc. Natl Acad. Sci. USA 98(19), 10869-10874 (2001).

190 Cronin M, Pho M, Dutta D et al. Measurement of gene expression in archival paraffin-embedded tissues: development and performance of a 92-gene reverse transcriptase polymerase chain reaction assay. Am. J. Pathol. 164, 35-42 (2004).

191 Paik S, Shak S, Tang G et al. A multigene assay to predict recurrence of tamoxifentreated, node-negative breast cancer. $N$. Engl. J. Med. 351, 2817-2826 (2004).

192 Paik S, Shak S, Tang G et al. Expression of the 21 genes in the Recurrence Score assay and prediction of clinical benefit from tamoxifen in NSABP study B-14 and chemotherapy in NSABP study B-20 (Abstract). 27th Annual San Antonio Breast Cancer Symposium, (2004)

193 Mauriac L, Durand M, Avril A, Dilhuydy JM. Effects of primary chemotherapy in conservative treatment of breast cancer patients with operable tumors larger than $3 \mathrm{~cm}$. Results of a randomized trial in a single centre. Ann. Oncol. 2, 347-354 (1991).

194 Mauriac L, MacGrogan G, Avril A et al. Neoadjuvant chemotherapy for operable breast carcinoma larger than $3 \mathrm{~cm}$ : a unicentre randomized trial with a 124 month median follow-up. Institut Bergonie Bordeaux Group Sein (IBBGS). Ann. Oncol. 10, 47-52 (1999).

195 Makris A, Powles TJ, Ashley SE et al. $A$ reduction in the requirements for mastectomy in a randomized trial of neoadjuvant chemoendocrine therapy in primary breast cancer. Ann. Oncol. 9 , 1179-1184 (1998).

196 Scholl SM, Fourquet A, Asselain B et al. Neoadjuvant versus adjuvant chemotherapy in premenopausal patients with tumors considered too large for breast conserving surgery: preliminary results of a randomized trial: S6. Eur. J. Cancer 30A, 645-652 (1994).

197 van der Hage JA, van de Velde CJ, Julien JP et al. Preoperative chemotherapy in primary operable breast cancer: results from the European Organization for Research and Treatment of Cancer trial 10902. J. Clin. Oncol. 19, 4224-4237 (2001).
198 Noguchi M, Earashi M, Fujii H et al. Radiofrequency ablation of small breast cancer followed by surgical resection. J. Surg. Oncol. 93, 120-128 (2006).

199 Jeffrey SS, Birdwell RL, Ikeda DM et al. Radiofrequency ablation of breast cancer. First report of an emerging technology. Arch. Surg. 134, 1064-1068 (1999).

200 Hayashi AH, Silver SF, van der Westhuizen NG et al. Treatment of invasive breast carcinoma with ultrasound guided radiofrequency ablation. $A m$. J. Surg. 185, 429-435 (2003).

201 Wu F, Wang ZB, Cao YD et al. A randomized clinical trial of high-intensity focused ultrasound ablation for the treatment of patients with localized breast cancer. Br. J. Cancer 89, 2227-2233 (2003).

202 Cionini L, Pacini P, Marzano S. Exclusive brachytherapy after conservative surgery in cancer of the breast (Abstract). Lyon Chir. 89, 128 (1993).

203 Fentiman IS, Deshmane V, Tong D et al. Caesium (137) implant as sole radiation therapy for operable breast cancer: A phase II trial. Radiother. Oncol. 71, 281-285 (2004).

204 King TA, Bolton JS, Kuske RR et al. Long-term results of wide-field brachytherapy as the sole method of radiation therapy after segmental mastectomy for $\mathrm{T}($ is, 1,2$)$ breast cancer. Am. J. Surg. 180, 299-304 (2000).

205 Polgar C, Sulyok Z, Fodor J et al. Sole brachytherapy of the tumor bed after conservative surgery for $\mathrm{T} 1$ breast cancer: Five-year results of a Phase I-II study and initial findings of a randomized Phase III trial. J. Surg. Oncol. 80, 121-128 (2002).

206 Vicini FA, Remouchamps V, Wallace MR et al. Ongoing clinical experience utilizing $3 \mathrm{D}$ conformal external beam radiotherapy to deliver partial-breast irradiation in patients with early-stage breast cancer treated with breast-conserving thearpy. Int . J. Radiat. Oncol. Biol. Phys. 57, 1247-1253 (2003).

207 Veronesi U, Orecchia R, Luini A et al. Full-dose intraoperative radiotherapy with electrons during breast conserving surgery: experience with 590 cases. Ann. Surg. 242(1), 101-106 (2005).

208 Vicini FA, Kestin L, Chen P et al. Limitedfield radiation therapy in the management of early stage breast cancer. J. Natl Canc. Inst. 95, 1205-1210 (2003).

209 Perera F, Engel J, Holliday R et al. Patterns of breast recurrence in a pilot study of brachytherapy confined to the lumpectomy 
site for early breast cancer with 6 years minimum follow-up. Int. J. Radiat. Oncol. Biol. Phys. 57, 1239-1246 (2003).

210 Arthur D, Koo D, Zwicker R et al. Partial breast brachytherapy after lumpectomy: low-dose rate and high-dose rate experience. Int. J. Radiat. Oncol. Biol. Phys. 56, 681-689 (2003).

211 Shah NM, Tenenholz T, Aurthur D et al. MammoSite and interstitial brachytherapy for accelerated partial breast irradiation: factors that affect toxicity and cosmesis. Cancer 101, 727-734 (2004).

212 Richards GM, Berson AM, Rescigno J et al. Acute toxicity of high-dose-rate intracavitary brachytherapy with the MammoSite applicator in patients with early-stage breast cancer. Ann. Surg. Oncol. 11, 739-746 (2004).
213 Formenti SC, Truong MT, Goldberg JD et al. Prone accelerated partial breast irradiation after breast-conserving surgery: Preliminary clinical results and dose-volume histogram analysis. Int. J. Radiat. Oncol. Biol. Phys. 60, 493-504 (2004).

214 Kuske RR, Winter K, Arthur D et al. A phase II trial of brachytherapy alone following lumpectomy for stage I or II breast cancer: initial outcomes of RTOG 95-17. Proc. Am. Soc.Clin. Oncol. 23(18) 565 (2004).

215 Kuske RR, Winter K, Arthur D et al. A phase II trial of brachytherapy alone following lumpectomy for stage I or II breast cancer: initial outcomes of RTOG 9517. J. Clin. Oncol. 23, 18 (2004).

216 Krag DN, Julian TB, Harlow SP et al. NSABP-32: Randomized trial comparing axillary resection with sentinel lymph node dissection: a description of the trial. Ann. Surg. Oncol. 11, 208S-210S (2004).
217 Costa A, Zurrida S, Gatti G et al. Less aggressive surgery and radiotherapy is the way forward. Curr. Opin. Oncol. 16, 523-528 (2004).

218 Wetzig N, Gill G, Ung O et al. Eligibility and choice in the Royal Australasian College of Surgeons SNAC trial of sentinel node biopsy versus axillary clearance in operable breast cancer. 3rd International Sentinel Node Biopsy Annual Congress. Yokohama, Japan, 2002.

\section{Affiliation}

- $\quad$ Michael S Sabel, MD, FACS University of Michigan Comprehensive Cancer Center, 3304 Cancer Center, Division of Surgical Oncology, 1500 East Medical Center Drive, Ann Arbor, MI 48109, USA Tel.: +17349365827 Fax: +17346479647 msabel@umich.edu 